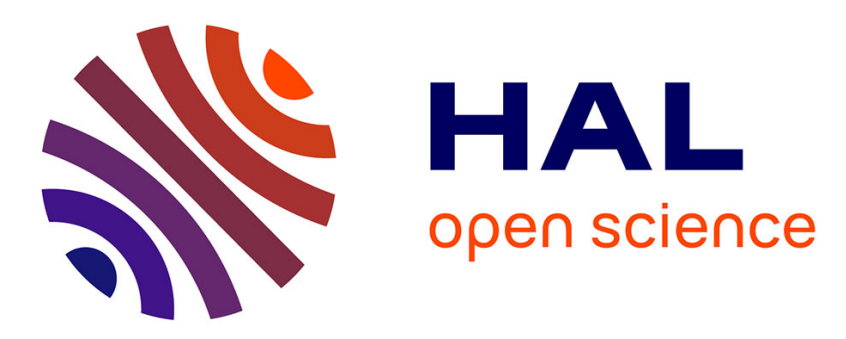

\title{
Energy Scheduling of a Smart Microgrid with Shared Photovoltaic Panels and Storage: the Case of the Ballen Marina in Sams $\varnothing$
}

Raffaele Carli, Mariagrazia Dotoli, Jan Jantzen, Michael Kristensen, Sarah Ben Othman

\section{To cite this version:}

Raffaele Carli, Mariagrazia Dotoli, Jan Jantzen, Michael Kristensen, Sarah Ben Othman. Energy Scheduling of a Smart Microgrid with Shared Photovoltaic Panels and Storage: the Case of the Ballen Marina in Sams $\varnothing$. Energy, 2020, 10.1016/j.energy.2020.117188 . hal-02550603

\section{HAL Id: hal-02550603 https://hal.science/hal-02550603}

Submitted on 22 Apr 2020

HAL is a multi-disciplinary open access archive for the deposit and dissemination of scientific research documents, whether they are published or not. The documents may come from teaching and research institutions in France or abroad, or from public or private research centers.
L'archive ouverte pluridisciplinaire HAL, est destinée au dépôt et à la diffusion de documents scientifiques de niveau recherche, publiés ou non, émanant des établissements d'enseignement et de recherche français ou étrangers, des laboratoires publics ou privés. 


\title{
Energy Scheduling of a Smart Microgrid with Shared Photovoltaic Panels and Storage: the Case of the Ballen Marina in Samsø
}

\author{
Raffaele Carlia $^{\mathrm{a}^{*}}$, Mariagrazia Dotoli ${ }^{\mathrm{a}}$, Jan Jantzen ${ }^{\mathrm{b}, \mathrm{c}}$, Michael Kristensen ${ }^{\mathrm{c}}$, Sarah Ben Othman ${ }^{\mathrm{d}}$ \\ ${ }^{a}$ Electrical and Information Engineering Dept., Politecnico di Bari, via Orabona 4, 70125 Bari, Italy \\ ${ }^{\mathrm{b}}$ Dept. of Financial and Management Engineering, University of the Aegean, Chios, Greece \\ ${ }^{\mathrm{c}}$ Samso Energy Academy, Samsø, Denmark \\ ${ }^{\mathrm{d}}$ CRIStAL Laboratory, Ecole-Central of Lille, Lille, France \\ * corresponding author: email: raffaele.carli@poliba.it
}

\begin{abstract}
This paper focuses on the Model Predictive Control (MPC) based energy scheduling of a smart microgrid equipped with non-controllable (i.e., with fixed power profile) and controllable (i.e., with flexible and programmable operation) electrical appliances, as well as photovoltaic (PV) panels, and a battery energy storage system (BESS). The proposed control strategy aims at a simultaneous optimal planning of the controllable loads, the shared resources (i.e., the storage system charge/discharge and renewable energy usage), and the energy exchange with the grid. The control scheme relies on an iterative finite horizon on-line optimization, implementing a mixed integer linear programming energy scheduling algorithm to maximize the self-supply with solar energy and/or minimize the daily cost of energy bought from the grid under timevarying energy pricing. At each time step, the resulting optimization problem is solved providing the optimal operations of controllable loads, the optimal amount of energy to be bought/sold from/to the grid, and the optimal charging/discharging profile for the BESS.

The proposed energy scheduling approach is applied to the demand side management control of the marina of Ballen, Samsø (Denmark), where a smart microgrid is currently being implemented as a demonstrator in the Horizon2020 European research project SMILE. Simulations considering the marina electric consumption (340 boat sockets, a service building equipped with a sauna and a wastewater pumping station, and the harbour master's office equipped with a heat pump), PV production $(60 \mathrm{kWp})$, and the BESS ( $237 \mathrm{kWh}$ capacity) based on a public real dataset are carried out on a one year time series with a 1 hour resolution. Simulations indicate that the proposed approach allows $90 \%$ exploitation of the production of the PV plant. Furthermore, results are compared to a naïve control approach. The MPC based energy scheduling improves the self-supply by $1.6 \%$ compared to the naïve control. Optimization of the business economy using the MPC approach, instead, yields to $8.2 \%$ savings in the yearly energy cost with respect to the naïve approach.
\end{abstract}

Keywords- microgrid, demand side management, renewable energy, energy storage, energy management, on-line scheduling, model predictive control, optimization algorithm. 


\section{Nomenclature}

\begin{tabular}{|c|c|}
\hline \multicolumn{2}{|c|}{ Parameters and indices } \\
\hline $\mathcal{H}$ & Time horizon \\
\hline$h$ & Index of time slots \\
\hline$t$ & Time \\
\hline$H$ & Number of slots in the time horizon \\
\hline$\Delta h$ & Length of time slot \\
\hline$r$ & Forecasted energy produced by RES over the time horizon \\
\hline $\boldsymbol{b}$ & Forecasted NCL demand over the time horizon \\
\hline $\bar{L} / \underline{L}$ & Maximum/minimum CL tank capacity in the wastewater pumping station \\
\hline$w^{+}$ & Inflow wastewater profile over the time horizon \\
\hline$w$ & Maximum water flow that the pump can suck in one time slot \\
\hline $\bar{\omega}$ & Nominal energy consumption of the wastewater pump \\
\hline $\boldsymbol{T}^{e x t}$ & Forecasted outdoor temperature over the time horizon \\
\hline$\tau_{a}$ & Time constant of the first order dynamics of the service building indoor temperature \\
\hline$\pi_{a}$ & Heating gain of the heat pump in the service building \\
\hline $\boldsymbol{T}_{a}^{\min }, \boldsymbol{T}_{a}^{\max }$ & Lower and upper bounds of the service building indoor temperature comfort range over the time horizon \\
\hline $\bar{E}_{a}$ & Maximum energy level of the heat pump in the service building \\
\hline$\tau_{s}$ & Time constant of the first order dynamics of the sauna indoor temperature \\
\hline$\pi_{s}$ & Heating gain of the sauna \\
\hline $\boldsymbol{T}_{s}^{\min }, \boldsymbol{T}_{s}^{\max }$ & Lower and upper bounds of the sauna indoor temperature comfort range over the time horizon \\
\hline $\bar{E}_{s}$ & Maximum energy level of the sauna \\
\hline $\bar{s} / \underline{s}$ & Maximum charging/discharging rates of the shared BESS \\
\hline $\bar{S} / \underline{S}$ & Maximum/minimum battery capacity of the shared BESS \\
\hline$\eta^{+} / \eta^{-}$ & Charging/discharging battery efficiencies of the shared BESS \\
\hline $\bar{g} / \underline{g}$ & Maximum buyable/saleable energy from/to the power grid \\
\hline $\boldsymbol{k}^{+} / \boldsymbol{k}^{-}$ & Cost coefficients of buying/selling energy from/to the power grid over the time horizon \\
\hline$\Delta \tau_{a}^{\text {pre-heating }}$ & Duration of the HVAC pre-heating phase \\
\hline$\tau_{a}^{\text {start }} / \tau_{a}^{\text {stop }}$ & Beginning and ending times of the service building occupancy period \\
\hline$\Delta \tau_{s}^{\text {pre-heating }}$ & Duration of the sauna pre-heating phase \\
\hline$\tau_{s}^{\text {start }} / \tau_{s}^{\text {stop }}$ & Beginning and ending times of the sauna occupancy period \\
\hline
\end{tabular}

\section{Continuous decision variables}

$\boldsymbol{y} \quad$ Total energy consumption of controllable loads over the time horizon

$\boldsymbol{y}^{w} \quad$ Energy consumption of the wastewater pump over the time horizon

$\boldsymbol{y}^{a} \quad$ Energy consumption of the HVAC heat pump over the time horizon

$y^{s} \quad$ Energy consumption of the sauna over the time horizon

$\boldsymbol{l} \quad$ Wastewater tank level over the time horizon

$\boldsymbol{w}^{-} \quad$ Outflow wastewater profile over the time horizon

$\boldsymbol{T}_{a} \quad$ Service building indoor temperature profile over the time horizon

$\boldsymbol{T}_{a} \quad$ Sauna indoor temperature profile over the time horizon

$\boldsymbol{x}^{s+} / \boldsymbol{x}^{s^{-}} \quad$ Stored/released energy profile for the shared BESS over the time horizon

$s \quad$ Battery charge level profile for the shared BESS over the time horizon

$\boldsymbol{x}^{g+} / \boldsymbol{x}^{g-} \quad$ Energy bought/sold from/to the power grid over the time horizon

$\boldsymbol{x}^{g \delta} \quad$ Supporting variables aimed at modelling the energy exchange between the microgrid and the power grid

$\boldsymbol{x}^{a} \quad$ Supporting variable related to the energy scheduling formulation

Discrete decision variables

$\boldsymbol{\delta}^{s+} / \boldsymbol{\delta}^{s-} \quad$ Binary variables representing the charging or discharging mode of the shared BESS over the time horizon

$\boldsymbol{\delta}^{g+} / \boldsymbol{\delta}^{g-} \quad$ Binary variables representing the mode of buying or selling energy from/to the power grid over the time horizon $\delta^{\text {wp }} \quad$ Binary variable denoting the on/off state of the water pump 
$\delta^{h p} \quad$ Binary variable denoting the on/off state of the HVAC heat pump

$\delta^{\text {sh }} \quad$ Binary variable denoting the on/off state of the sauna heater

\section{Introduction}

Due to increasing concerns on environment sustainability, policy makers, researchers, and practitioners have recently devoted attention to strategic actions aimed at energy efficiency and energy savings [1]-[3]. The growing energy demand and penetration of renewable energies pose several challenges to grid operators and thus motivate the acclaimed roll-out of the smart grid concept [4]. This concept refers to the enhancement of the traditional power grid infrastructure, especially in terms of pervasive use of information and communications technologies [5]-[7]. Indeed, to reduce the generation of energy from fossil fuels and expand the use of renewable energy sources, new advanced solutions for the future power grids need to be explored [8]-[9]. Smart grids are also attractive from a management and control perspective, since decision and control actions aimed at optimally controlling power flows between components should be considered in order to achieve the economic and environmental profitability of their operations [10]. In particular, the motivation for moving from the traditional energy systems paradigm of "generation-follows-load" to the new paradigm of "load-follows-generation" has led to developing Demand Side Management (DSM) methodologies [11]. These methodologies play an important role for the sustainable development of both district heating [12] and electrical distribution networks [13]. The term DSM is generally used to indicate a set of actions aimed at efficiently controlling and managing the energy consumption of a site, mainly to decrease the costs incurred for the supply of electricity, including network and system charges, and reduce the need for investments in networks and/or power plants for meeting peak demands [14]. These optimization actions are aimed at modifying the characteristics of the energy consumption, in terms of the overall entity of consumption, time profile of consumption, and grid connection parameters, in order to bring the energy demand and supply closer to a perceived optimum [14].

In basic implementations of DSM, an in-depth analysis of energy consumption of a site (e.g., building, network of buildings, facility, district, etc.) allows determining its own peculiarities of each site and understanding if the consumption habits can be optimized without the use of additional tools [15]. Alternatively, the on-site installation of renewable sources (e.g., photo-voltaic panels, wind turbines), cogeneration plants as well as energy storage systems (e.g., electrochemical, thermal storages) -also known as distributed generation and storage- enables collection of energy from many sources and leads to lower environmental impacts while improving security of supply [16]. However, such a variety of small, gridconnected devices implies the need of an Energy Management System (EMS), which allows to monitor the dynamics of all the involved assets (loads, batteries, generators), optimize in real-time the performance of storage and generation systems, and leverage on deployed assets to provide the power grid with supplementary services [17]. Indeed, all these components must autonomously and efficiently cooperate for the optimal demand response of end-users and efficient interaction with power grid, smart appliances, renewable energy sources (RESs), battery energy storage systems (BESSs) and plug-in electric vehicles (PEVs) [14]. As a consequence, the necessity of developing an effective optimal energy scheduling framework tackling all these objectives is apparent.

Coping with this challenge, this paper focuses on the Model Predictive Control (MPC) based energy scheduling of a smart microgrid equipped with non-controllable (i.e., with fixed power profile) and controllable (i.e., with flexible and programmable operation) electrical appliances, as well as photovoltaic (PV) panels, and a BESS that allows storing surplus of energy for later use. The proposed control strategy aims at a simultaneous optimal planning of the controllable loads, the shared resources (i.e., the storage system charge/discharge and renewable energy usage), and the energy exchange with the grid. The control scheme relies on an iterative finite horizon on-line optimization, implementing a mixed integer linear programming energy scheduling algorithm to maximize the self-supply with solar energy and/or minimize the daily cost of energy bought from the grid under time-varying energy pricing. At each time step, the resulting optimization problem is solved providing the optimal operations of controllable loads, the optimal amount of energy to be bought/sold from/to the grid, and the optimal charging/discharging profile for the BESS. The proposed energy scheduling approach is applied to the demand side management control of the marina of Ballen, Samsø (Denmark), where a smart microgrid is currently being implemented as a demonstrator in the Horizon2020 European research project SMILE [54]. Simulations considering the marina electric consumption (340 boat sockets, a service building equipped with a sauna and a wastewater pumping station, and the Harbour Master's office equipped with a heat pump), PV production (60kWp), and the BESS (237kWh capacity) based on a real public dataset [59] are carried out on a one year time series with a 1 hour resolution. Simulations indicate that the proposed approach allows $90 \%$ exploitation of the production of the PV plant. Furthermore, results are compared to a naïve control approach. The MPC based energy scheduling improves the self-supply by $1.6 \%$ compared to the naïve control. Optimization of the business economy using the MPC approach, instead, yields to $8.2 \%$ savings in the yearly energy cost 
with respect to the naïve approach.

The remainder of this paper is organized as follows. Section II provides an overview of the literature on microgrid energy scheduling and positions the paper contribution. Section III describes the detailed model of the system under study. The naïve and MPC-based formulations of the scheduling problem are presented in Section IV and Section V, respectively. The case study results and analysis are provided in Section VI to demonstrate the benefits of the proposed strategy. Finally, the paper ends with conclusions and future work in Section VII.

\section{Related Works and Paper Contribution}

\subsection{Literature Review}

There is a large literature on energy management of microgrids. In the context of DSM, the aim of these systems is essentially to enable users to respond to market mechanisms and determine the optimal schedule of the energy activities. The literature reports several methods for energy scheduling. In general, two types of strategies can be found as described in detail in the sequel: offline scheduling [18]-[20] and real-time scheduling [22]-[30], [33]-[47]. In the offline setting, independently from the application area, the optimization is performed once for the whole time horizon prior to the start of the system operation. For example, an offline building energy management system is outlined in [18] to manage selected household loads according to customer preferences and the demand limit, aiming at reducing the demand and energy consumption costs. A similar smart energy management system is proposed in [19], where evolutionary optimization algorithms are proposed to schedule appliances of interconnected multiple homes. In [20] a day-ahead scheduling algorithm including power forecasting module, a BESS management module and an optimization module is implemented to minimize the total operational cost of an energy district.

In all the above works [18]-[20], the common approach mainly lies in the offline scheduling of energy activities, which is determined once for the whole period of the planning horizon. Consequently, addressing the underlying uncertainty of the problem parameters is not possible [21]. To cope with this, another class of studies adopts real-time strategies taking into account uncertainty on forecast data to achieve a more flexible and effective energy scheduling [22]-[30], [33]-[47]. For example, a real-time cost-efficient residential load scheduling framework is developed in [22] where cost efficiency can vary with different consumption patterns and is sensitive to behaviors of loads. Yang and Wang [23] address the trade-off between energy consumption and comfort level of smart building occupants using an innovative multi-objective evolutionary optimization algorithm. Arun and Selvan [24] propose a real-time load scheduling heuristic algorithm aimed at reducing the electricity bill and keep the total consumption under maximum demand limit considering the operating dynamics of a large number of controllable and non-controllable loads. Similarly, Lee et al. [25] present a hidden Markov model for the scheduling of shiftable loads in households equipped with storage systems. In addition, Ye et al. [26] address the real-time DSM of a microgrid equipped with renewable energy sources and storage systems, showing that a game theoretical energy scheduling enabled by an advanced communication networks is able to smooth peak-to-average ratio (PAR) of power usage. Similarly, Liu et al. [27] present a heuristic dynamic programming method to efficiently solve the real-time residential energy scheduling problem, while reducing the total electricity cost and improving load balancing process. Mahmud et al. [28] present an improved decision-tree-based algorithm to reduce the peak load in distribution networks including the coordinated control of PEVs. Rahimiyan and Baringo [29] address the case of a virtual power plant (VPP) composed by a cluster of demands, a storage unit, and a wind power plant. The VPP is managed by an EMS which can strategically buy and sell energy in the energy market to optimize the aggregated power traded and utility [29]. Finally, Fratean and Dobra [30] analyze the contribution of different control methods to decreasing the energy consumption and increasing self-consumption in nearly zero-energy buildings. Simulation results related to different scenarios show that the MPC control achieves the best performance with respect to control methods [30]. Not surprisingly, among several promising advanced control system approaches, MPC has recently gained special attention in DSM of microgrid, since it allows to explicitly account for respecting the dynamics and constraints of the system while optimizing some given criteria [31]. In effect, the hardware decreasing cost, data accessibility, and advances of Information and Communication Technology (ICT) and EMS, allow the collection, storage, and analysis of a vast amount of microgrid-related data that permit the implementation of prediction models for the optimal control of energy consumption and utilization of renewable energy [32].

Numerous publications on the use of MPC in residential microgrids have been proposed [33]-[42]. The MPC formulation can be used to control and optimize residential appliances [33]-[35], energy activities of single or sets of buildings interacting with smart grids [36]-[37], and microgrids equipped with on-site renewable energy sources as well as energy storage systems [38]-[42]. In general, MPC approaches are successfully applied in all the cases when energy resources must be optimally managed under designated constraints and model [43]. For instance, Kolokotsa et al. [33] present an MPC energy 
management solution to control the indoor environment while minimizing energy costs. Li et al. [34] propose a MPC based energy scheduling for the energy management of a smart home equipped with fixed and shiftable households, a renewable energy generator, and a storage device. Through a genetic algorithm, the resulting scheduler attempts to improve the utilization of renewable energy while reducing the cost payment of smart appliances by $11.5 \%$ compared to the no optimization case [34]. Similarly, Hosseini et al. [35] present a receding horizon on-line optimization stratetgy to minimize the electricity bill of the user's load demand under quadratic energy pricing and to limit the PAR of the energy consumption whilst considering operational constraints. The achieved schedule of energy exchanged with the main grid shows a $11.2 \%$ cheaper and $6.1 \%$ flatter profile with respect to an offline optimization procedure [35]. Long et al. [36] propose a MPC framework for a microgrid containing multiple energy vectors. The results related to a scenario of three interconnected buildings shows that the average daily cost saving achieved by optimal control is approximately 50\%. [36]. Nguyen et al. [37] present a multilevel optimal control formulation for a microgrid of prosumers, leveraging on the flexibility of local generation and consumption to minimize the supply from the main grid and taking the limitation of the distribution network capacity into account [37]. Yang et al. [38] propose a MPC-based approach to minimize the operation cost of a microgrid equipped with fixed loads, EVs, and batteries, considering the uncertainties both in supply and demand sides of the system. The resulting daily total energy cost decreases by $9.7 \%$ compared to the no optimization case [38]. Prodan and Zio [39] show that MPC is a viable approach for the optimal energy management of a microgrid equipped with a consumer, a wind generator and a battery, accounting for costs reduction and profile shaping. Simulation results highlight that the ratio between the yearly power taken from the wind generator and yearly cumulative available wind power is increased by $121 \%$ compared to the use of reinforcement learning algorithm [39]. Du et al. [40] propose a two-layer distributed MPC scheme to optimize the supply and demand profile from the economic perspective, while improving the renewable energy utilization of distributed microgrid systems. The resulting daily total energy cost is reduced by $19.1 \%$ compared to the uncoordinated mode of operations [40]. Finally, another class of studies related to residential energy management addresses microgrids operating in islanded mode (i.e., disconnected from the power grid) [41]-[42]. In such studies the objective of the on-line optimization is focused on the reliability of operations of the microgrid, since the connection with the utility grid is not available and the supplied energy mainly comes from highly variables sources such as solar and wind.

Consistently with the above discussed approaches, the application of intelligent DSM to industrial microgrids has also gained momentum in the scientific research and industry as well [44]. Numerous publications on the use of MPC in industrial microgrids have been proposed in [44]-[47], showing that, in accordance with dynamic time-variant electricity costs, it is highly profitable also for such users to reschedule and shift energy demand to periods with low rates.

\subsection{Paper Contribution and Positioning}

The previous discussion of literature review shows that the suitability of MPC to tackle DSM has been proven both theoretically and through experiments, mostly on buildings [30], [33]-[42] and on an industrial scale [44]-[47]. Despite this broad area of applications, the formulation of MPC algorithms for DSM of non-residential and non-industrial facilities has not been thoroughly investigated. Furthermore, in all the cited works on MPC [30], [33]-[42], [44]-[47], the performance of the proposed control algorithms is assessed on a limited period of time: typically the analysis is performed on a simulation horizon of one day. On the one hand, such a horizon is enough to show the effectiveness of optimal control with respect to other scheduling techniques. On the other hand, due to the possibly high variability of consumption and generation curves, the assessment of the potentiality of scheduling algorithms requires to be extended on larger time window of analysis. Moreover, only the economic benefits of the control strategies are commonly assessed, whilst the potential of the control strategies potential in the framework of demand side management for better matching of demand and supply is not explicitly evaluated.

Summing up, the contributions of this paper with respect to the related and cited literature may be summarized as follows.

From a theoretical point of view, we present a comprehensive and general model and a systematic methodology to state and solve the optimal energy scheduling problem of a grid-connected microgrid incorporating the flexibility of loads. The microgrid shares a RES and a BESS under a dynamic pricing. However, the microgrid is also able to sell its extra energy back to the grid by a dynamic linear pricing. Our proposed framework is generic and flexible as it can be applied to different structures of microgrids considering various types of components. Furthermore, in the formulation of the energy scheduling problem we propose two alternative definitions of the objective function corresponding to different goals to be pursued in the optimal energy management of the microgrid: the energy cost minimization and the self-reliance maximization.

From a practical perspective, we deal with the effectiveness and the potential of the proposed approach on a sample microgrid related to the marina of Ballen, Samsø (Denmark). In particular, through an experimental study using real data, we tangibly evaluate the contribution of the MPC control strategies in optimizing the performance of the given microgrid system 


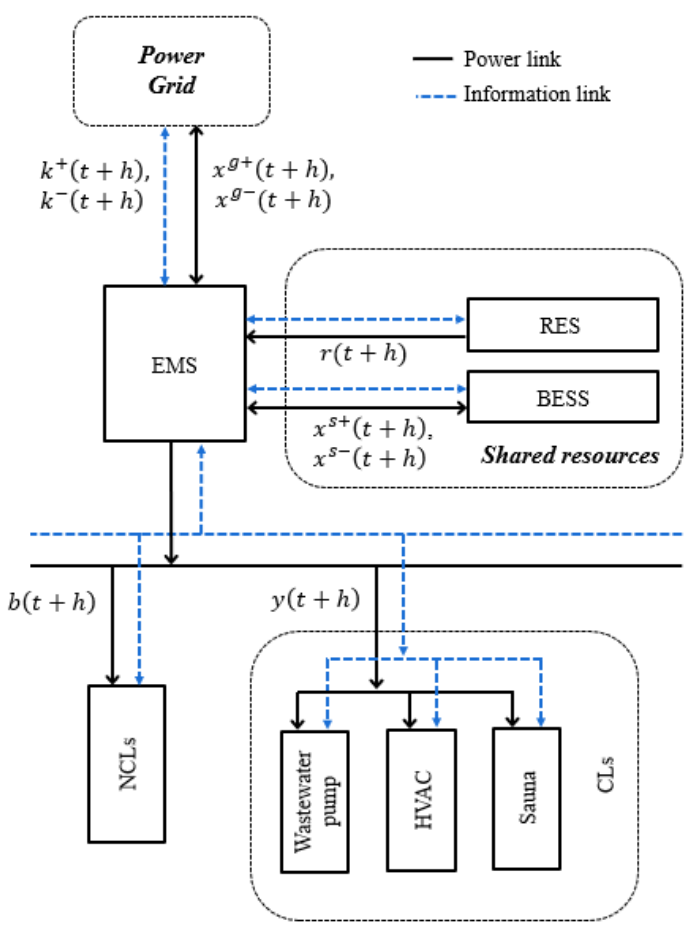

Fig. 1. Microgrid of the marina: scheme of energy flows and connections between distribution network, energy system components, and shared devices.

(e.g., reducing the energy cost and increasing the consumption of locally produced energy). We show that the proposed MPC strategy leads to optimal load shifting and storage charging/discharging; in addition, thanks to our approach and using good predictions in MPC-based control, a better matching of demand and supply can be achieved, raising energy efficiency and improving grid reliability when there is a high penetration of intermittent energy resources. Furthermore, a comprehensive comparison between our proposed MPC energy scheduling and a naïve control approach without any prediction model is also provided, confirming the effectiveness of the proposed optimal control method.

\section{System Model}

In this section we present a mathematical model related to the microgrid of a marina, which is aimed at formulating the energy scheduling problem for the electrical appliances and the shared resources, i.e., the RES and the BESS as well as the demand-supply balance and constraints.

We consider the marina as a small port area including facilities such as docks equipped with electrical sockets for boats, a service building used by sailors, and an office building for the harbour master. The architecture of the marina energy system is shown in Fig. 1. The activities of the microgrid are controlled by the EMS that is also in charge of acquiring pricing signals from the power grid and managing the operations of shared resources. A digital communication infrastructure is implemented to connect all the microgrid components to the energy management system.

The control outputs are the profile of energy exchanged with the power grid, the scheduling of the controllable loads, and the charging/discharging strategy of the BESS. At the generic time $t$, we consider a time window $\mathcal{H}(t) \triangleq$ $\{t+1, \ldots, t+h, \ldots, t+H\}$ including $H$ discrete time slots with equal length $\Delta h$. The value of the forward-looking objective function related to the time horizon is repetitively optimized at subsequent time slot, but only the decision variable values of the first time step are applied according to receding horizon concept [48]. In the following, vectors are denoted by bold letters.

The modeling of system components is discussed as follows.

\subsection{Uncontrollable Loads}

First of all, we assume that the microgrid is equipped with non-controllable loads (NCLs), which are inflexible loads whose operation time cannot be shifted and profile cannot be modulated (i.e., with fixed power profile). Illustrative examples in this 
category are the lighting appliances in service buildings and harbor master's office, outdoor street lighting over the marina facilities, and boat sockets. We define for each time slot a column vector of $H$ inputs $\boldsymbol{b}(t) \triangleq[b(t+1) ; \ldots ; b(t+$ $h) ; \ldots ; b(t+H)]$ collecting the cumulative energy profile of the non-controllable loads consumption in the time window $\mathcal{H}(t)$. We assume that this vector is computed by a forecast sub-module of the EMS (see Fig. 1), using a prediction algorithm based on historical data.

\subsection{Controllable Loads}

We assume that the microgrid is also equipped with controllable loads (CLs), which are loads with flexible and programmable operation. Such controllable loads can be operated on a favorable schedule. Due to their flexibility, these loads aid the EMS to mitigate any eventual power imbalance in the system by controlling and shifting variations in the demand. Controllable loads can be commonly categorized into two different classes [49]:

1. Energy-based CLs - These appliances are characterized by a prescribed energy requirement (e.g., pumps of waters supply networks, EVs), i.e., a certain amount of energy has to be consumed over a set of time slots delimited by a minimum starting-time slot and a maximum ending-time slot.

2. Comfort-based CLs - These devices consume energy to control a physical variable influencing the user's comfort (e.g., heating, ventilation and air conditioning (HVAC) systems, refrigerators).

Without loss of generality, we assume that in the microgrid three CLs are identified: an HVAC heat pump serving the harbour master's office, an electrically heated sauna (comfort-based CLs) located in the service building, and a wastewater pumping station (energy-based CL) serving the toilets and showers of the service building. In the following sections we provide the detailed model of these three CLs. Indeed, these models can be straightforwardly modified to contemplate other different applications.

To model the scheduling activities of CLs within the time windows, we define a vector $\boldsymbol{y}(t) \triangleq[y(t+1) ; \ldots ; y(t+h)$; ...; $y(t+H)$ ] collecting the $H$ decision variables over the horizon, where $y(t+h)$ is the energy totally required by all the CLs at any time slot $t+h$, such that:

$$
y(t+h)=y^{w}(t+h)+y^{a}(t+h)+y^{s}(t+h), h \in \mathcal{H}(t)
$$

where $y^{w}(t+h), y^{a}(t+h)$, and $y^{s}(t+h)$ denote the energy consumption of the wastewater pump, HVAC heat pump, and sauna at time slot $t+h$, respectively.

\subsubsection{Water Pumping Station}

A water pumping station can act as an energy-based CL. Water from effluent, drainage and sewage of a given facility flows to an underground tank. A pump sends the water to a collector tank, from which then water flows to the processing plant. Since water is stored in the tank, the pump can be operated on a favorable schedule. For example, the pump could be run during the night to help discharge the battery before sunrise, so that the latter is ready to store a new day's solar energy.

The dynamics of the tank filling/emptying process can be written as a first order discrete time state model as follows [46]:

$$
l(t+h)=l(t+h-1)+w^{+}(t+h)-w^{-}(t+h), h \in \mathcal{H}(t)
$$

where $l(t+h), w^{+}(t+h)$ and $w^{-}(t+h)$ respectively denote the tank level, inflow and outflow (measured in liters) for time slot $t+h$, respectively. The tank level is bounded by the minimum and maximum tank capacity $\underline{L}$ and $\bar{L}$ as follows:

$$
\underline{L}-l(t+h-1) \leq w^{+}(t+h)-w^{-}(t+h) \leq \bar{L}-l(t+h-1), h \in \mathcal{H}(t) .
$$

Note that, on the one hand, vector $\boldsymbol{w}^{+}(t) \triangleq\left[w^{+}(t+1) ; \ldots ; w^{+}(t+h) ; \ldots ; w^{+}(t+H)\right]$ collecting the inflow profile in the time window $\mathcal{H}(t)$ is an input parameter. On the other hand, vector $\boldsymbol{w}^{-}(t) \triangleq\left[w^{-}(t+1) ; \ldots ; w^{-}(t+h) ; \ldots ; w^{-}(t+\right.$ $H)$ ] collecting the outflow profile in the time window $\mathcal{H}(t)$ has to be determined based on an energy consumption criterion. Vector $\boldsymbol{w}^{-}(t)$ has to be computed in accordance with the following bounding constraint:

$$
0 \leq w^{-}(t+h) \leq \underline{w}, h \in \mathcal{H}(t) .
$$

where $\bar{W}$ is the maximum inflow amount of water that the pump can suck in one time slot with duration $\Delta h$.

Denoting by $\omega$ the nominal energy consumption of the pump (measured in Wh/liter), the energy consumption profile of the water pump over the time window $\mathcal{H}(t)$ - denoted as $\boldsymbol{y}^{w}(t) \triangleq\left[y^{w}(t+1) ; \ldots ; y^{w}(t+h) ; \ldots ; y^{w}(t+H)\right]$ - is written as follows:

$$
y^{w}(t+h)=\omega w^{-}(t+h), h \in \mathcal{H}(t) .
$$




\subsubsection{HVAC Based on Heat Pump}

HVAC systems play an important role in maintaining acceptable hygrothermal and air quality conditions in indoor building environments. Such systems can be controlled to ensure energy-efficient building operations while ensuring that energy efficiency does not affect the occupants' well-being.

Given the service building of the marina, the following discrete time model can be used to represent the indoor temperature [50]:

$$
T_{a}(t+h)=e^{\Delta h / \tau_{a}} T_{a}(t+h-1)+\left(1-e^{\Delta h / \tau_{a}}\right)\left(T^{e x t}(t+h)-\pi_{a} y^{a}(t+h)\right), h \in \mathcal{H}(t)
$$

where $T_{a}(t+h)$ and $T_{\text {ext }}(t+h)$ are the building indoor and outdoor temperature at time slot $t+h$, respectively, $\tau_{a}$ is the constant time of the first order dynamic of the building zone temperature, and $\pi_{a}$ is the temperature gain of the heat pump. Note that vector $\boldsymbol{T}^{\text {ext }}(t) \triangleq\left[T^{\text {ext }}(t+1) ; \ldots ; T^{\text {ext }}(t+h) ; \ldots ; T^{\text {ext }}(t+H)\right]$ collecting the outdoor temperature profile in the time window $\mathcal{H}(t)$ is an input parameter, computed using weather prediction data. Conversely, vector $\boldsymbol{T}_{a}(t) \triangleq$ $\left[T_{a}(t+1) ; \ldots ; T_{a}(t+h) ; \ldots ; T_{a}(t+H)\right]$ collecting the building temperature profile is a variable of the problem. Vector $\boldsymbol{T}_{a}(t)$ has to be computed in accordance with the following constraint:

$$
T_{a}^{\text {min }}(t+h) \leq T_{a}(t+h) \leq T_{a}^{\max }(t+h), h \in \mathcal{H}(t)
$$

where $\quad \boldsymbol{T}_{a}^{\min }(t) \triangleq\left[T_{a}^{\min }(t+1) ; \ldots ; T_{a}^{\min }(t+h) ; \ldots ; T_{a}^{\min }(t+H)\right] \quad$ and $\quad \boldsymbol{T}_{a}^{\max }(t) \triangleq\left[T_{a}^{\max }(t+1) ; \ldots ; T_{a}^{\max }(t+\right.$ $\left.h) ; \ldots ; T_{a}^{\max }(t+H)\right]$ denote the vectors of lower and upper bounding of the indoor temperature, respectively. Range $\left[T_{a}^{\min }(t+h), T_{a}^{\max }(t+h)\right](h \in \mathcal{H}(t))$ is a time-varying parameter that allows building occupants to represent thermal comfort preferences within the occupancy period. Similarly, vector $\boldsymbol{y}^{a}(t) \triangleq\left[y^{a}(t+1) ; \ldots ; y^{a}(t+h) ; \ldots ; y^{a}(t+H)\right]$ collecting the heat pump consumption profile is a variable of the problem. Vector $\boldsymbol{y}^{a}(t)$ has to be computed in accordance with the following constraint:

$$
0 \leq y^{a}(t+h) \leq \bar{E}_{a}, h \in \mathcal{H}(t)
$$

where $\bar{E}_{a}$ is the maximum energy that the pump can consume in one time slot with duration $\Delta h$.

\subsubsection{Sauna Heater}

The modeling of a sauna is similar to the HVAC heat pump. The following discrete time model can be used to represent the indoor temperature of the sauna [50]:

$$
T_{s}(t+h)=e^{\Delta h / \tau_{s}} T_{s}(t+h-1)+\left(1-e^{\Delta h / \tau_{s}}\right)\left(T^{e x t}(t+h)-\pi_{s} y^{s}(t+h)\right), h \in \mathcal{H}(t)
$$

where $T_{s}(t+h)$ is the sauna indoor temperature at time slot $t+h, \tau_{s}$ is the constant time of the first order dynamic of the sauna temperature, and $\pi_{s}$ is the temperature gain of the sauna heat pump. Note that vector $\boldsymbol{T}_{s}(t) \triangleq\left[T_{s}(t+1) ; \ldots ; T_{s}(t+\right.$ $h) ; \ldots ; T_{s}(t+H)$ ] collecting the sauna temperature profile is a variable of the problem. Vector $\boldsymbol{T}_{s}(t)$ has to be computed in accordance with the following constraint:

$$
T_{s}^{\min }(t+h) \leq T_{s}(t+h) \leq T_{s}^{\max }(t+h), h \in \mathcal{H}(t)
$$

where $\quad \boldsymbol{T}_{s}^{\min }(t) \triangleq\left[T_{s}^{\min }(t+1) ; \ldots ; T_{s}^{\min }(t+h) ; \ldots ; T_{s}^{\min }(t+H)\right] \quad$ and $\quad \boldsymbol{T}_{s}^{\max }(t) \triangleq\left[T_{s}^{\max }(t+1) ; \ldots ; T_{s}^{\max }(t+\right.$ $\left.h) ; \ldots ; T_{s}^{\max }(t+H)\right]$ denote the vectors of lower and upper bounding of the sauna indoor temperature, respectively. Range $\left[T_{s}^{\min }(t+h), T_{s}^{\max }(t+h)\right](h \in \mathcal{H}(t))$ is a time-varying parameter that allows sauna users to represent thermal comfort preferences within the period of use. Similarly, vector $\boldsymbol{y}^{s}(t) \triangleq\left[y^{s}(t+1) ; \ldots ; y^{s}(t+h) ; \ldots ; y^{s}(t+H)\right]$ collecting the sauna heat pump consumption profile is a variable of the problem. Vector $\boldsymbol{y}^{s}(t)$ has to be computed in accordance with the following constraint:

$$
0 \leq y^{s}(t+h) \leq \bar{E}_{s}, h \in \mathcal{H}(t)
$$

where $\bar{E}_{s}$ is the maximum energy that the sauna pump can consume in one time slot with duration $\Delta h$.

\subsection{Shared Renewable Energy Sources}

We assume that the microgrid incorporates one shared RES, (e.g., a PV system). We define for each time slot a column vector of $H$ input parameters $\boldsymbol{r}(t) \triangleq[r(t+1) ; \ldots ; r(t+h) ; \ldots ; r(t+H)]$ collecting the profile of energy produced by the 
RES in the time window $\mathcal{H}(t)$. This vector is assumed to be calculated by a forecast sub-module of the EMS using a prediction algorithm based on weather data.

\subsection{Shared Battery Energy Storage System}

The shared BESS unit provides flexibility to the microgrid in the energy scheduling. Here the shared BESS is modeled as in [49]. The shared BESS should optimally store energy from the PV plant and the grid ahead of time and consume it during peak hours when the grid load demand is high. To model the charging/discharging activities of the BESS within the time windows, we define two vectors $x^{s+}(t) \triangleq\left[x^{s+}(t+1) ; \ldots ; x^{s+}(t+h) ; \ldots ; x^{s+}(t+H)\right]$ and $\boldsymbol{x}^{s-}(t) \triangleq\left[x^{s-}(t+\right.$ $\left.1) ; \ldots ; x^{s-}(t+h) ; \ldots ; x^{s-}(t+H)\right]$, each collecting $H$ decision variables, where $x^{s+}(t+h) / x^{s-}(t+h)$ is the energy stored/released in/from the battery at any time slot $t+h$. Due to the conversion losses of the BESS, we define $\eta^{+}$and $\eta^{-}$as the charging and discharging efficiencies, respectively.

The dynamics of the charge/discharge level of the small scale BESS for time slot $t+h$ can be written as a first order discrete time model as follows [49]:

$$
s(t+h)=s(t+h-1)+\eta^{+} x^{s+}(t+h)-x^{s-}(t+h) / \eta^{-}, h \in \mathcal{H}(t)
$$

where $s(t+h)$ denotes the charge level of the BESS at time slot $t+h$. In this work, we assume that the battery degradation and leakage effects are negligible. The maximum charge/discharge level is bounded by the minimum and maximum battery capacity $\underline{S}$ and $\bar{S}$ as follows:

$$
\underline{S}-s(t+h-1) \leq \eta^{+} x^{s+}(t+h)-x^{s-}(t+h) / \eta^{-} \leq \bar{S}-s(t+h-1), h \in \mathcal{H}(t) .
$$

Denoting $\bar{s}$ and $\underline{s}$ as the maximum charging and discharging rates, the following technical constraints must be satisfied:

$$
\begin{aligned}
& 0 \leq x^{s+}(t+h) \leq \delta^{s+}(t+h) \bar{s}, h \in \mathcal{H}(t) \\
& 0 \leq x^{s-}(t+h) \leq \delta^{s-}(t+h) \underline{s}, h \in \mathcal{H}(t)
\end{aligned}
$$

where $\boldsymbol{\delta}^{s+}(t) \triangleq\left[\delta^{s+}(t+1) ; \ldots ; \delta^{s+}(t+h) ; \ldots ; \delta^{s+}(t+H)\right]$ and $\boldsymbol{\delta}^{s-}(t) \triangleq\left[\delta^{s-}(t+1) ; \ldots ; \delta^{s-}(t+h) ; \ldots ; \delta^{s-}(t+H)\right]$ are two vectors of supporting binary variables, respectively introduced to avoid the simultaneous charging and discharging of the BESS:

$$
\begin{gathered}
\delta^{s+}(t+h) \in\{0,1\}, \delta^{s-}(t+h) \in\{0,1\}, h \in \mathcal{H}(t) \\
\delta^{s+}(t+h)+\delta^{s-}(t+h) \leq 1, h \in \mathcal{H}(t) .
\end{gathered}
$$

\subsection{Grid Energy Flow and Associated Cost}

To impose the power balance in the system, a demand-supply balance constraint should be fulfilled at each time slot $h$. As in [52], we introduce $\boldsymbol{x}^{g+}(\mathrm{t}) \triangleq\left[x^{g+}(t+1) ; \ldots ; x^{g+}(t+h) ; \ldots ; x^{g+}(t+H)\right]$ and $\boldsymbol{x}^{g-}(\mathrm{t}) \triangleq\left[x^{g-}(t+1) ; \ldots ; x^{g-}(t+\right.$ $\left.h) ; \ldots ; x^{g-}(t+H)\right]$ that are column vectors of $H$ decision variables modeling the energy profile bought/sold from/to the power grid within the time window, respectively. The following balance equation must be thus satisfied:

$$
b(t+h)+\mathrm{y}(t+h)-r(t+h)+x^{s+}(t+h)-x^{s-}(t+h)=x^{g+}(t+h)-x^{g-}(t+h), h \in \mathcal{H}(t) .
$$

Furthermore, we assume that the exchange of energy between the microgrid and power grid occurs in a single direction at each time slot (i.e., the power grid cannot simultaneously sell and buy energy to/from the microgrid). The pricing of energy bought/sold from/to the power grid are modeled as piece-wise linear with respect to time [53]. As a consequence, the energy cost incurred by the microgrid to exchange the energy amount $x^{g+}(t+h)-x^{g-}(t+h)$ with the power grid over the time slot $t+h$ can be expressed as:

$$
c\left(x^{g+}(t+h), x^{g-}(t+h)\right)=k^{+}(t+h) x^{g+}(t+h)-k^{-}(t+h) x^{g-}(t+h), h \in \mathcal{H}(\mathrm{t})
$$

where $\boldsymbol{k}^{+}(t) \triangleq\left[k^{+}(t+1) ; \ldots ; k^{+}(t+h) ; \ldots ; k^{+}(t+H)\right]$ and $\boldsymbol{k}^{-}(t) \triangleq\left[k^{-}(t+1) ; \ldots ; k^{-}(t+h) ; \ldots ; k^{-}(t+H)\right]$ are two column vectors collecting the known time-varying cost coefficients of buying/selling energy from/to the power grid, respectively.

Denoting by $\bar{g}$ and $\underline{g}$ respectively the maximum purchasable and salable energy profile imposed by the energy provider, 


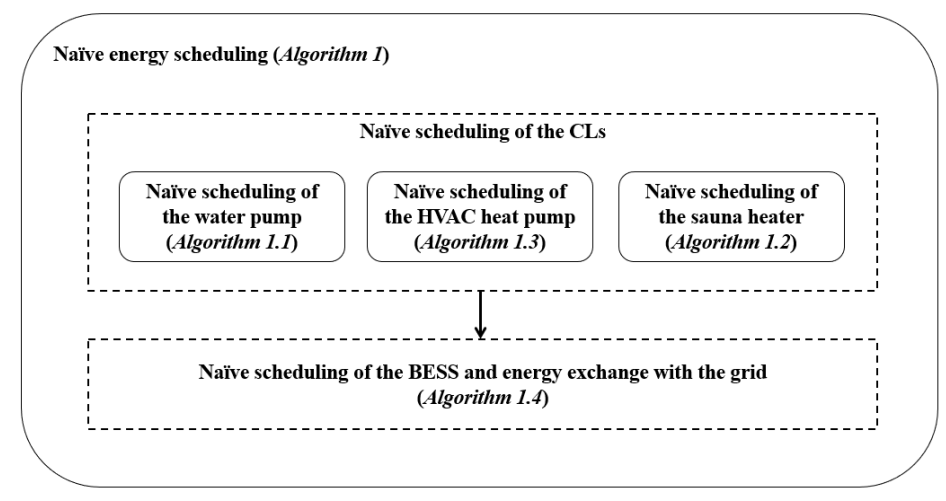

Fig. 2. High level scheme of the proposed naïve energy scheduling (Algorithm 1) .

the following technical constraints must be satisfied:

$$
\begin{aligned}
& 0 \leq x^{g+}(t+h) \leq \delta^{g+}(t+h) \bar{g}, h \in \mathcal{H}(t) \\
& 0 \leq x^{g-}(t+h) \leq \delta^{g-}(t+h) \underline{g}, h \in \mathcal{H}(t)
\end{aligned}
$$

where $\boldsymbol{\delta}^{g+}(t) \triangleq\left[\delta^{g+}(t+1) ; \ldots ; \delta^{g+}(t+h) ; \ldots ; \delta^{g+}(t+H)\right]$ and $\boldsymbol{\delta}^{g-}(t) \triangleq\left[\delta^{g-}(t+1) ; \ldots ; \delta^{g-}(t+h) ; \ldots ; \delta^{g-}(t+H)\right]$ are two vectors of supporting binary variables introduced to avoid simultaneously buying and selling energy from/to the power grid [52]:

$$
\begin{gathered}
\delta^{g+}(t+h) \in\{0,1\}, \delta^{g-}(t+h) \in\{0,1\}, h \in \mathcal{H}(t) \\
\delta^{g+}(t+h)+\delta^{g-}(t+h) \leq 1, h \in \mathcal{H}(t) .
\end{gathered}
$$

\section{Naïve Energy Scheduling Strategy}

For the sake of defining a baseline strategy, in this section we describe the simplest possible approach for determining time slot-by-time slot the amount of energy to be consumed by each CL, the amount of energy to be charged/discharged into/from the BESS, and the amount of bought/sold from/to the grid.

The proposed naïve control strategy is formally expressed by Algorithm 1 (Fig. 2). This algorithm is composed by two stages: the naïve scheduling of CLs and the scheduling of the BESS and energy exchange with the grid.

As for the first stage, the naïve scheduling of CLs comprises the following activities: the naïve scheduling of the water pump, the HVAC heat pump, and the sauna heater, defined by Algorithm 1.1, 1,2 and 1.3, respectively.

The proposed naïve control strategy of the water pump (Algorithm 1.1) comprises the following logic. As soon as the water level in the tank is lower than the maximum allowed level, the pump is kept switched-off (line 4). Note that in Algorithm $1.1 \delta^{w p}$ is a binary variable denoting the on/off state of the water pump ( 1 is on, 0 is off). Once the water level exceeds the maximum allowed level (line 5), the pump is switched-on. Once the water level is greater than the minimum level, the pump is kept switched-on (line 8). Once the water level drops to the minimum level (line 9), the pump is switched-off. The current outflow is determined in accordance with the on/off state of the pump (line 13), and consequently the associated energy consumption is computed (line 14). Finally, the current level of water in the tank is updated (line 15), and the algorithm steps are repeated at each time slot (lines 3 and 16-17).

The proposed naïve control strategy of the HVAC heat pump (Algorithm 1.2) is based on the following two considerations. First, when no occupant is in the building (i.e., outside the period of building occupancy), the heat pump must be kept switched-off to avoid wasting energy. Second, to ensure a suitable comfort to occupants, the heat pump must preheat the building. In particular, Algorithm 1.2 comprises the following logics. Note that in Algorithm $1.2 \delta^{h p}$ is a binary variable denoting the on/off state of the heat pump ( 1 is on, 0 is off), $\tau_{a}^{\text {start }}$ and $\tau_{a}^{\text {start }}$ respectively denote the beginning and ending of the nearest building occupancy period, and $\Delta \tau_{a}^{\text {pre-heating }}$ is the duration of the pre-heating phase. As soon as the current time slot is outside both the pre-heating and the occupancy period, the heat pump is kept switched-off (line 6-7 and 16-18). Once the current time enters the pre-heating period (line 8), the pump is switched-on. Instead, once the current time enters the occupancy period (lines 10-16), the pump is switched-on (switched-off), if the indoor temperature is below (above) the 
comfort temperature (i.e., the median of the temperature comfort range). The current heat pump energy consumption is determined in accordance with the on/off state of the pump (line 19) the algorithm steps are repeated at each time slot (lines 3 and 20-21).

The proposed naïve control strategy of the sauna heater (Algorithm 1.3) is similar to the naïve control strategy of the HVAC heat pump. For the sake of brevity, Algorithm 1.3 is thus not detailed.

As for the scheduling of the BESS and energy exchange with the grid, the proposed naïve control strategy (Algorithm 1.4) is based on the following two considerations. First, the microgrid should sell energy to the power grid as a last chance, since the selling price is generally lower than the buying price, and the use of the locally generated renewable energy contributes to maximizing the self-supply. Second, the microgrid cannot avoid buying energy from the power grid, since the overall production of the shared RES does not match the total annual demand. In particular, Algorithm 1.4 implements the following logic. The current demand is determined as the aggregation of the amount of energy required by the NCLs (i.e., $b(\cdot))$ and the amount of energy determined by the naïve scheduling of CLs (i.e., outputs of algorithms 1.1, 1.2, and 1.3). On the one hand, if the available renewable energy is greater than the demand (lines 4-12), the surplus is used to charge the battery (line 8). If this is already full (line 10) or the surplus is greater than the charging rate, the excess energy is sold to the grid (line 12). On the other hand, if the demand is greater than the available renewable energy (lines 13-22), the difference is supplied by discharging the battery (line 17). If the storage charge is not sufficient (line 19), then the remaining needed energy is imported from the grid (line 21). Finally, the current state of charge of the battery is updated (line 23), and the algorithm steps are repeated at each time slot (lines 2 and 24-25).
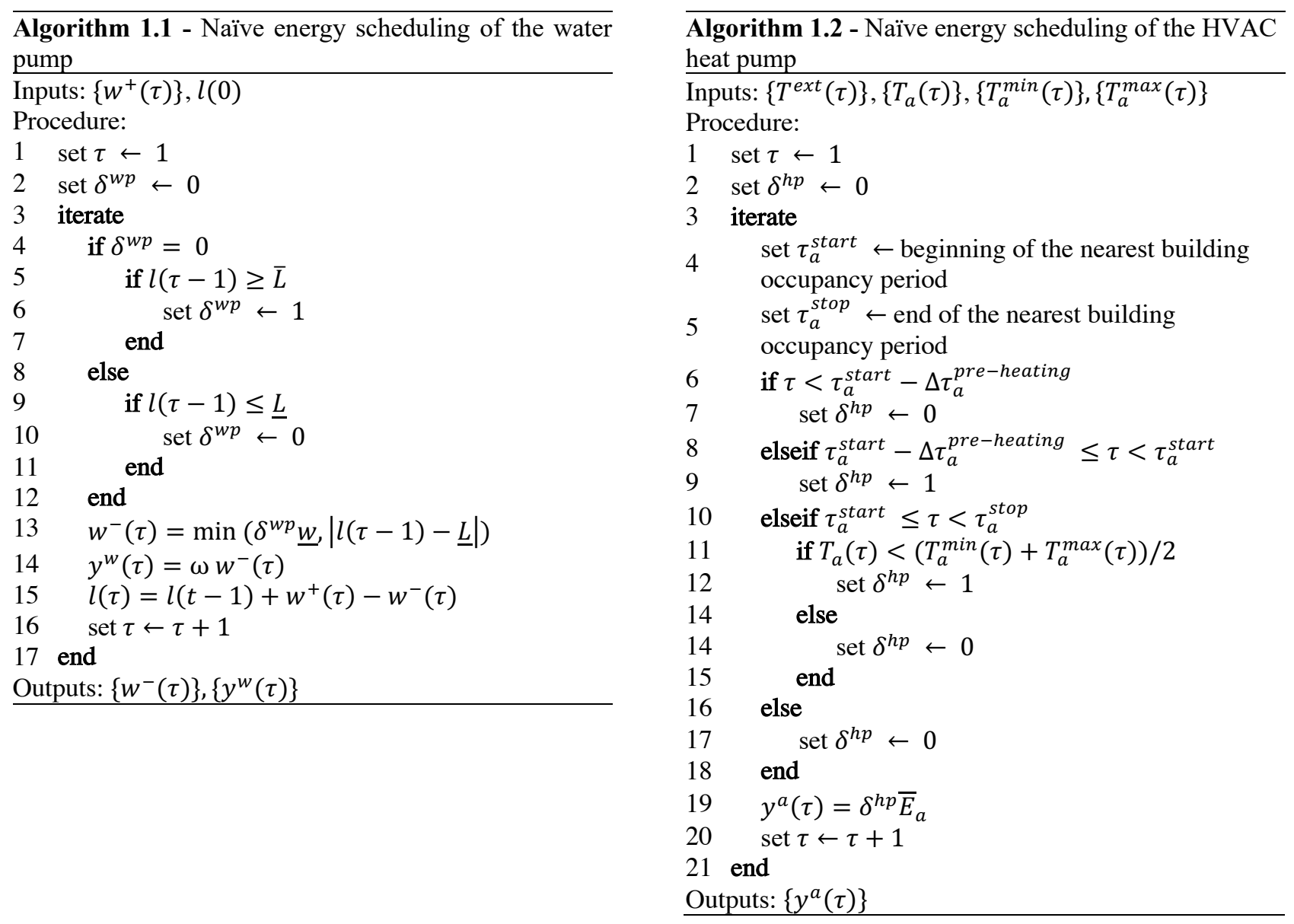

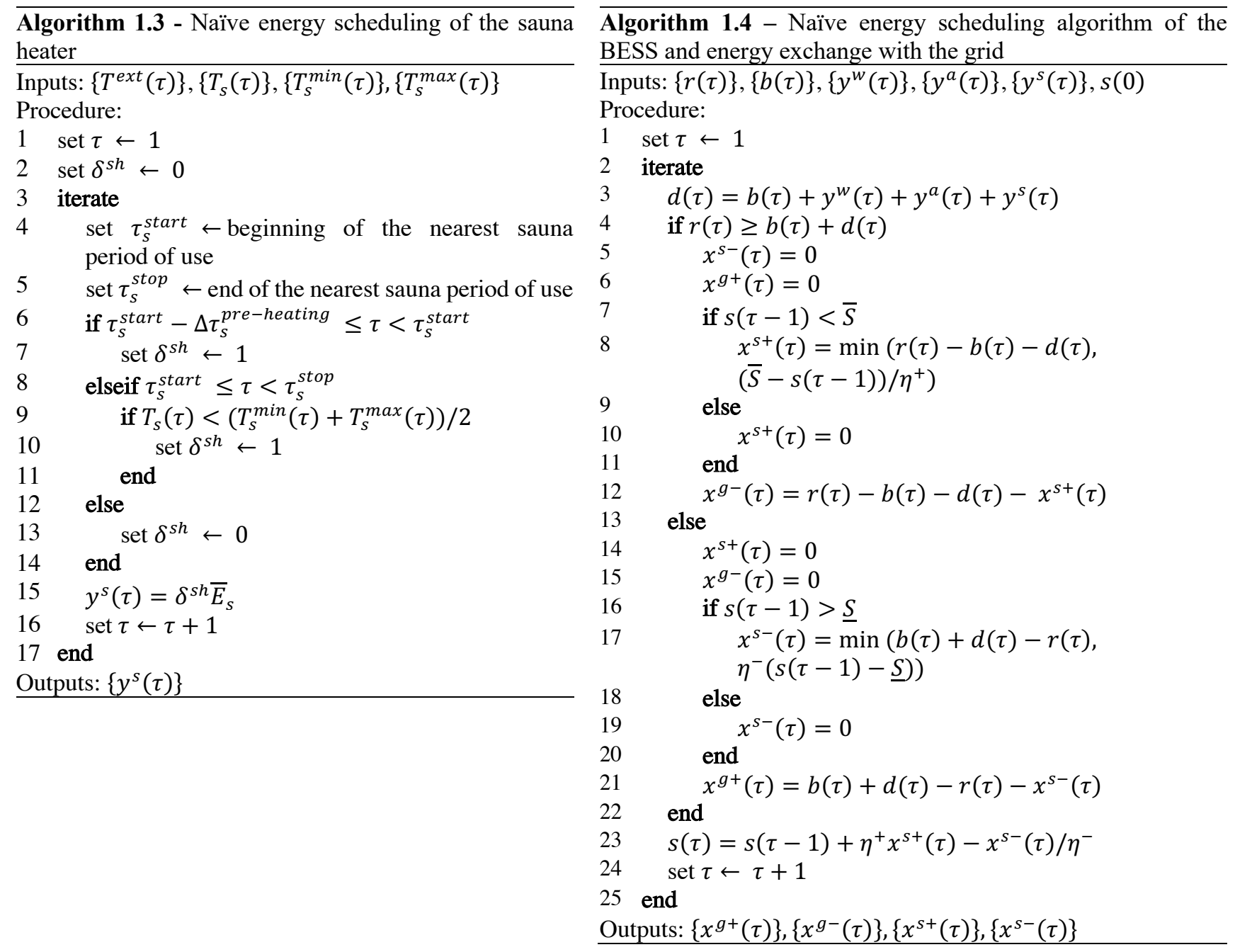

\section{MPC Energy Scheduling Strategy}

Model Predictive Control has recently become particularly attractive for the control of smart energy systems due to its capability of merging principles of feedback control and numerical optimization. In effect, MPC is able to use both predictions of future disturbances (e.g., demand fluctuations, weather, etc.) and given requirements (e.g., comfort ranges), to anticipate the energy needs of a system and optimize its operations on the basis of the defined goals. Generally speaking, the MPC technique is based on three elements: (1) an explicit dynamical model of the system, which is used to predict the system behavior in response to future actions, (2) two time horizons over which the behavior of the system is predicted and controlled (often the two horizons coincide), (3) a time step, in which an optimization problem, based on the dynamical model, is solved so as to optimize the performance of the system over the chosen control horizon. At each time step, the system behavior is observed and information on its state is collected and used to update the corresponding dynamical model. Then the optimization problem is stated and solved over the time horizon and the results are applied to the system in a closed-loop control fashion. Indeed, the results of the optimization consist in proper control actions that are applied to the system only in the subsequent time step. The procedure is then iteratively executed until the end of the time interval of interest.

In the following we presents the mathematical formulation of the proposed MPC scheme for the microgrid of a marina. Differently from the naïve case, we first formulate a finite horizon open-loop optimization problem for the optimal scheduling of the microgrid energy activities under the modeled dynamics and operational constraints of all the system components. Subsequently, we solve at each time step the defined optimization problem according to the receding horizon principle.

The reason for applying a more advanced scheduling algorithm is illustrated by the following examples: if the PV forecast for tomorrow is low, it is better to charge the battery from the grid during the night when the price is low; even though the wastewater tank is not totally empty, it is better to operate the pump at night when the price is low. These examples also 


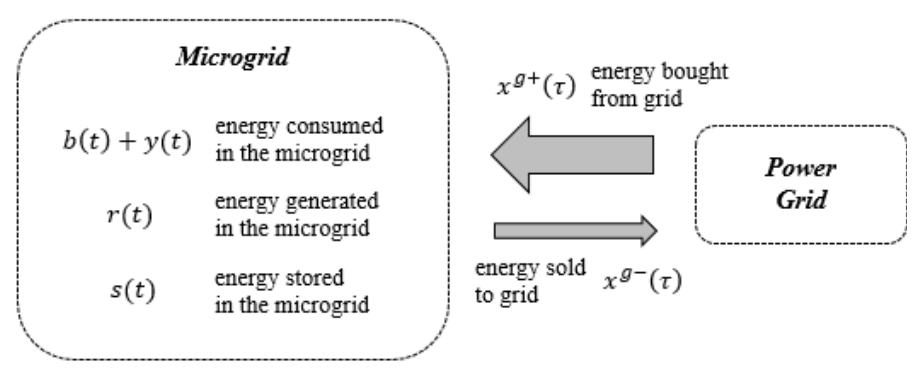

Fig. 3. System model for evaluating microgrid self-reliance.

show that the MPC approach relies on the availability of models (e.g., model of the BESS based on the charge level as state variable, model of the wastewater tank based on the level as state variable) and prediction data (e.g., PV production curve, wastewater inflow profile, energy pricing).

\subsection{Online Optimization Problem}

Having modeled all the energy flows and costs in the considered time window, we now define the optimal control strategy that allows the microgrid to compute the optimal operations of the CLSs and BESS and strategies for buying/selling energies from/to the grid. In particular, we formulate two alternative optimization problems based on two common design objectives in a microgrid system: energy cost minimization and self-reliance maximization.

In the former case, an efficient energy scheduling can be formulated in terms of minimizing the energy costs to all the system components, considering as objective function the cost incurred by the microgrid to exchange the energy profile $\boldsymbol{x}^{g+}(t)-\boldsymbol{x}^{g-}(t)$ with the power grid over the whole time window $\mathcal{H}(\mathrm{t})$ :

$$
C\left(\boldsymbol{x}^{g+}(t), \boldsymbol{x}^{g-}(t)\right)=\sum_{h=1}^{H}\left(k^{+}(t+h) x^{g+}(t+h)-k^{-}(t+h) x^{g-}(t+h)\right) .
$$

In the second case, an efficient energy scheduling can be formulated in terms of maximizing the self-reliance of the microgrid over the whole time window $\mathcal{H}(\mathrm{t})$ :

$$
R\left(\boldsymbol{x}^{g+}(t), \boldsymbol{x}^{g-}(t)\right)=\sum_{h=1}^{H}\left|x^{g+}(t+h)-x^{g-}(t+h)\right|=\sum_{h=1}^{H}\left(x^{g+}(t+h)+x^{g-}(t+h)\right) .
$$

Note that maximizing the self-reliance corresponds to minimizing the exchanges with the main grid, i.e., the microgrid operates in islanded mode when possible, by using only the internal energy produced by RES and receiving the least power from the main grid (Fig. 3). For this reason, in (25) the objective function is defined as is the sum of unsigned flows from/to main grid.

The general energy scheduling problem can be compactly written as follows:

$$
\begin{gathered}
\operatorname{opt} \\
\boldsymbol{y}^{w}(t), \boldsymbol{w}^{-}(t), \boldsymbol{y}^{a}(t), \boldsymbol{T}_{a}(t), \boldsymbol{y}^{s}(t), \boldsymbol{T}_{s}(t), \\
\boldsymbol{x}^{s+}(t), \boldsymbol{x}^{-}(t), \boldsymbol{x}^{g+}(t), \boldsymbol{x}^{g-}(t), \\
\boldsymbol{\delta}^{s+}(t), \boldsymbol{\delta}^{s-}(t), \boldsymbol{\delta}^{g+}(t), \boldsymbol{\delta}^{g-}(t) \\
\text { s.t. (1)-(18), (20)-(23). }
\end{gathered}
$$

Problem (26) is a mixed integer linear programming problem that consists in determining the $10 \mathrm{H}$ real decision variables in $\boldsymbol{y}^{w}(t), \boldsymbol{w}^{-}(t), \boldsymbol{y}^{a}(t), \boldsymbol{T}_{a}(t), \boldsymbol{y}^{s}(t), \boldsymbol{T}_{s}(t), \boldsymbol{x}^{s+}(t), \boldsymbol{x}^{s-}(t), \boldsymbol{x}^{g+}(t), \boldsymbol{x}^{g-}(t)$ and $4 H$ binary decision variables in $\boldsymbol{\delta}^{s+}(t), \boldsymbol{\delta}^{s-}(t), \boldsymbol{\delta}^{g+}(t), \boldsymbol{\delta}^{g-}(t)$, which meet the recalled $12 H$ bounding constraints, $7 H$ inequality constraints, and $4 H$ equality constraints in (1)-(18), (20)-(23) and optimize the linear objective function $F(\cdot)$ defined as $C(\cdot)$ in (24) (to be minimized) or $R(\cdot)$ in (25) (to be maximized).

\subsection{MPC Algorithm}

The online optimization problem (26) is solved iteratively at each time slot $t$ in accordance with the receding horizon principle until the simulation end time. The resulting MPC algorithm is formally defined by Algorithm 2 and described in the sequel. At each time instant $t$, the following steps are repeated as time goes on (lines 2 and 8). First, the EMS receives 


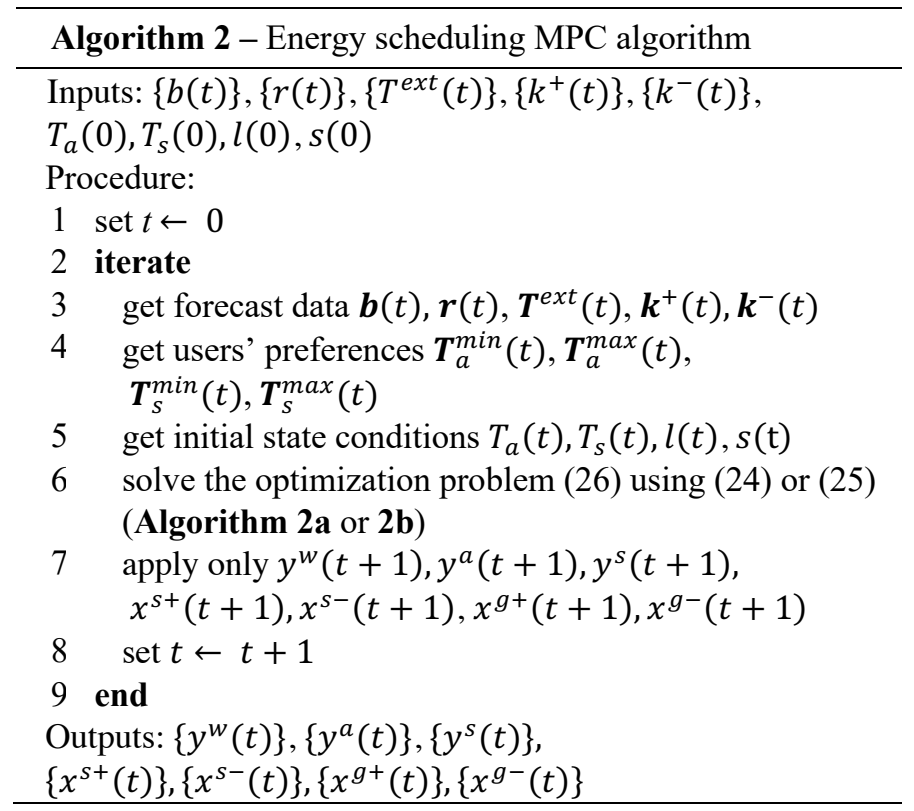

the updated predictions related to the NCLs consumption, RES production, outdoor temperature, main grid pricing coefficients (line 3), the updated profiles of users' preferences for service building and sauna (line 4), and the updated initial values of state variables for building and sauna indoor temperature, storage charge level and water tank level (line 5). Second, the online optimization problem (26) is solved (line 6). Hence, the optimization results related to the first time step are extracted from the determined optimal decision variables and these values are applied to the system in a closed-loop control fashion (line 7). As a final remark, we highlight that the online optimization problem (26) is assumed to be feasible over all the iterations.

\section{Case Study}

In this section we show the performance of the proposed MPC algorithm through numerical experiments. Specifically, we consider a period of analysis of one year (i.e., $\mathcal{T}=[0,8,784]$ ) with a prediction horizon of $H=24$ hours (i.e., $\mathcal{H}(\mathrm{t})=[\mathrm{t}+$ $1, t+24])$ and a sampling time of 1 hour. The obtained results are reported in the sequel and are analyzed and compared with the previously defined naïve control strategy. In particular, five different cases are analyzed (Table 1). In the first case the naïve control strategy is used (scenario I). In the second and third one we apply a combined approach: the naïve approach is used to schedule CLs and the determined CLs profile is added to the NCLs; then, the proposed MPC-based method aimed at energy cost minimization (scenario II.a) and self-reliance maximization (scenario II.b) to schedule only BESS and exchange with the main grid. Finally, in the fourth and fifth case we use the proposed MPC-based method aimed energy cost minimization (scenario III.a) and self-reliance maximization (scenario III.b) applied to schedule both CLs, BESS and exchange with the main grid.

The scheduling problems in Table 1 are solved by CPLEX 12.8 [55] in MATLAB R2018b on a desktop PC equipped with an Intel i7 core $2.70 \mathrm{GHz}$ processor and $16 \mathrm{~GB}$ RAM memory. The total computational runtime for simulating the whole period of one year (i.e., 8,784 optimization runs) is about 250 seconds. The proposed MPC algorithm takes less than a second to optimize a 24-hour horizon.

\subsection{Parameters and Settings}

The case study microgrid (see Fig. 4) is the Ballen marina located in Samsø (Denmark), where a smart energy system is being installed and tested in the framework of the Horizon2020 European research project SMILE [54]. Samsø was appointed in 1997 as Denmark's renewable energy island and has been the site for many energy innovations which are leading the island to be fossil fuel free by 2030 [56]-[58]. Today, the annual energy demand balances the annual supply from RES (sometimes the island produces more electricity than it consumes owing to offshore and onshore wind power, and a district heating based on biomass) but the island is currently not self-sufficient, yet. In the framework of SMILE [54], the main goal 


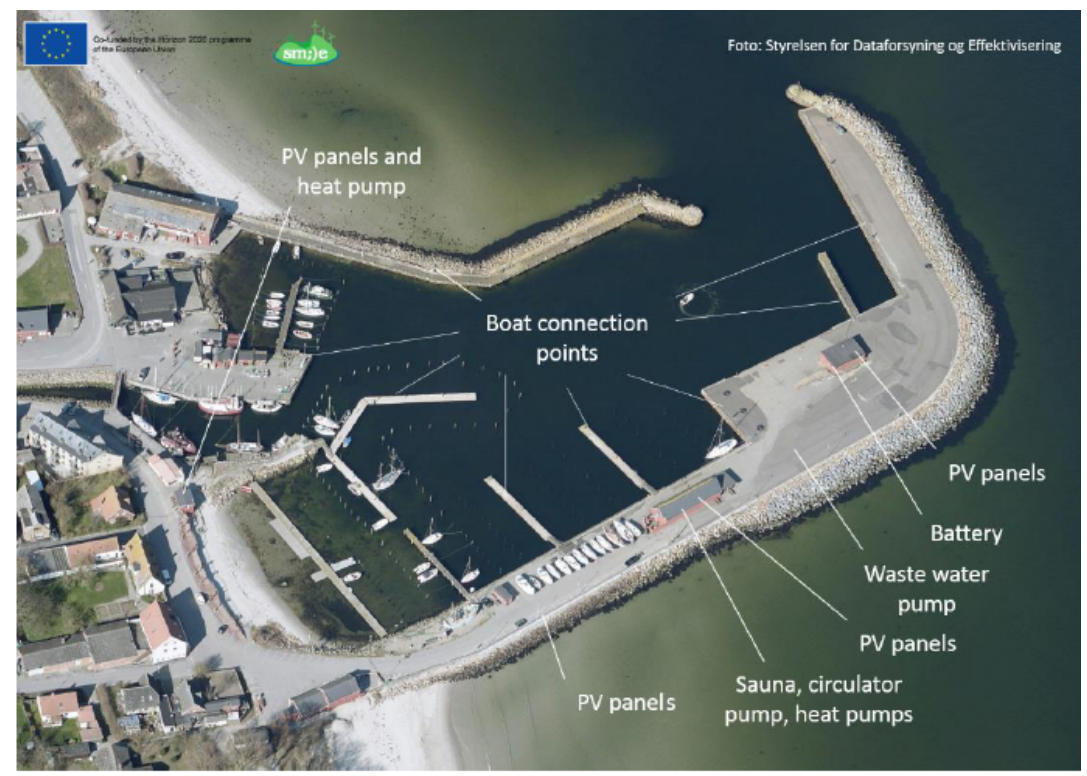

Fig. 4. Overview of the Ballen marina (DK) with its smart energy components [54].

for Samsø is to make better use of the green electricity produced on the island, minimizing the electricity export. The main objective of such a project is to foster the market introduction of smart grid technologies and demonstrate them through system prototype deployment in a relevant environment. Specific objectives for the Samsø municipality are: to install a PV power generation system covering part of the heating demand in the harbour master's office using renewable energy and a new heat pump; to install a battery system to level out fluctuations in supply and demand in the marina microgrid; to develop and test an overall control system, which allows demand side management based on dynamic market pricing.

In this paper we focus on the electric system of the marina of Sams $\varnothing$, which mainly includes a PV plant (60 kWp), a BESS $(237 \mathrm{kWh})$, the inflexible demand from the harbour master's office, service building, and visiting boats (105,000 $\mathrm{kWh} /$ year) as well as demand for CLs (water pumping station, HVAC system, and sauna). The system is connected to the public electricity supply. Figure 4 shows all the components of the smart energy system marked on an aerial photograph.

Simulations are based on a real data set, which is public [59]. In particular, the electricity consumption of the marina NCLs and the PV production concern data measured in 2016 (see Fig. 5). Figure 5a shows a large peak in the summer period, when many boats visit the marina. during the rest of the year the load is moderate. This is partially counterbalanced by the PV panels, which start the highest production in May. In particular, during December, January, and February the production is about one tenth of the production in May. Anyway, the demand peak is so large that the PV panels are unable to fully cover the demand, implying the need of further energy coming from storage and/or the main grid.

Table 1. Cases of analysis

\begin{tabular}{|c|c|c|c|}
\hline & \multicolumn{2}{|c|}{ Scheduling output } & \multirow{2}{*}{$\begin{array}{l}\text { Scenario } \\
\text { identifier }\end{array}$} \\
\hline & CLs & BESS and exchange with grid & \\
\hline \multirow{5}{*}{$\begin{array}{l}\text { Scheduling } \\
\text { method }\end{array}$} & \multicolumn{2}{|r|}{$\begin{array}{c}\text { Naïve } \\
\text { (Algorithm 1) }\end{array}$} & $\mathrm{I}$ \\
\hline & $\begin{array}{c}\text { Naïve } \\
\text { (Algorithms 1.1-1.3) }\end{array}$ & $\begin{array}{l}\text { MPC with energy cost minimization } \\
\text { (Algorithm 2a) }\end{array}$ & II.a \\
\hline & $\begin{array}{c}\text { Naïve } \\
\text { (Algorithms 1.1-1.3) }\end{array}$ & $\begin{array}{c}\text { MPC with self-reliance maximization } \\
\text { (Algorithm } 2 \mathrm{~b} \text { ) }\end{array}$ & II.b \\
\hline & \multicolumn{2}{|c|}{$\begin{array}{l}\text { MPC with energy cost minimization } \\
\text { (Algorithm 2a) }\end{array}$} & III.a \\
\hline & \multicolumn{2}{|c|}{$\begin{array}{l}\text { MPC with self-reliance maximization } \\
\text { (Algorithm } 2 \mathrm{~b} \text { ) }\end{array}$} & III.b \\
\hline
\end{tabular}


The BESS parameters are set as follows: the minimum and maximum allowed charging levels are respectively $\underline{S}=0$ and $\bar{S}=237 \mathrm{kWh}$; the charging/discharging rates $(\bar{s}$ and $\underline{s})$ are limited by the inverter, whose in/out capacity is $49 \mathrm{kWh}$; the charging and discharging efficiencies $\left(\eta^{+}\right.$and $\left.\eta^{-}\right)$are both equal to $97 \%$. At the beginning of the period of analysis the storage state of charge is assumed to be empty $(s(0)=0)$.

The microgrid is not allowed to sell energy from battery to the grid. For this reason, the maximum salable energy profile $\underline{g}$ is set to $(r(t)-b(t))$. No limitation is imposed on buying energy from the grid; thus, the maximum purchasable $\bar{g}$ is set to a large number.

The price of electricity follows the spot price on the Nord Pool electricity market. The prices are hourly prices on the socalled DK1 market, which is the western part of Denmark [60]. The buying price (i.e., $k^{+}(\cdot)$ ) is approximately the Nord Pool spot price plus taxes and fees equal to $0.03 \mathrm{EUR} / \mathrm{kWh}$ (see Fig. 6), while selling price (i.e., $k^{-}(\cdot)$ ) is the spot price.

The outdoor temperature is relevant for estimating heat consumption. The outdoor temperature (i.e., $\left.T^{\text {ext }}(\cdot)\right)$ was measured 10 kilometres from the Ballen marina in 2016 and measurements are averaged over every hour (see Fig. 7).

As for the wastewater pumping station, the parameters are set as follows. The volume of the tank 4.5 cubic meters. The maximum allowed water level is set to $\bar{L}=3 \mathrm{~m}^{3}$, whilst the tank is allowed to be totally empty, i.e., $\underline{L}=0 \mathrm{~m}^{3}$. The pump power is $3.4 \mathrm{kWh}$, whilst the flow rate is $1,200 \mathrm{l} / \mathrm{h}$. The daily wastewater inflow is estimated assuming in average $8-10$ showers per days (10 liters/minute), which occur more frequently at early morning and late afternoon.

As for the harbour master's office, it is open from $7 \mathrm{am}$ to $16 \mathrm{pm}$ on working days during winter and every day during the other seasons. Office occupants use heating mode of operation of the HVAC system only, imposing the thermal comfort in the range $[19-22]{ }^{\circ} \mathrm{C}$. The settling time of the office is estimated at 1.5 hour, whilst the electric consumption of heat pump

(a)

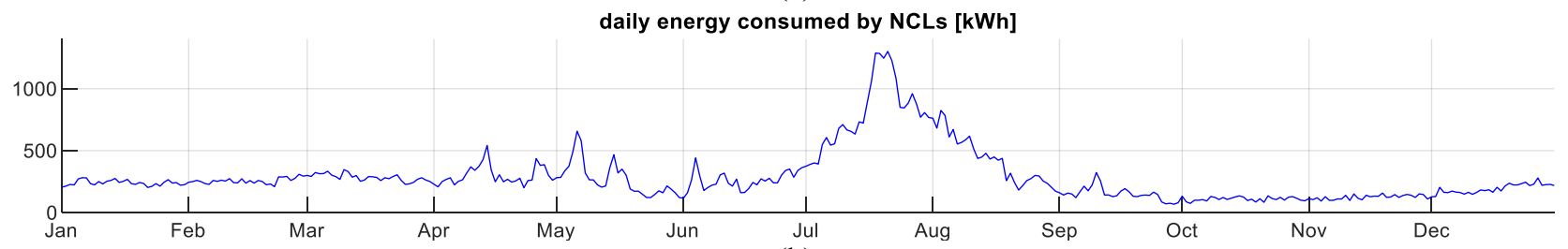

(b)

daily energy produced by PV panels [kWh]

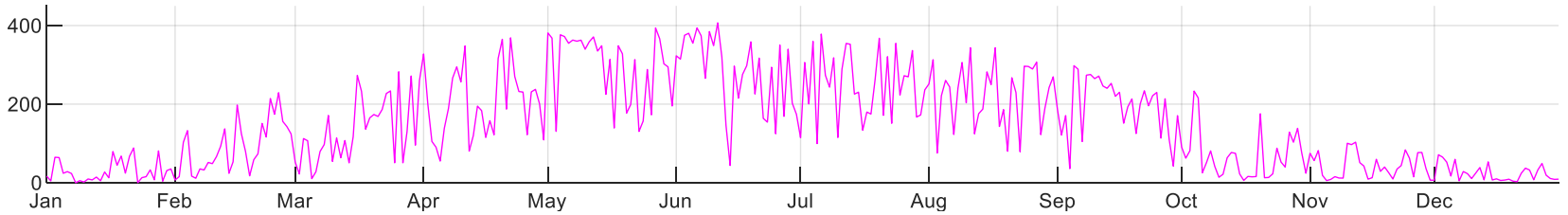

Fig. 5. Daily energy consumption profile of NCLs (a) and daily energy production profile of PV panels (b).

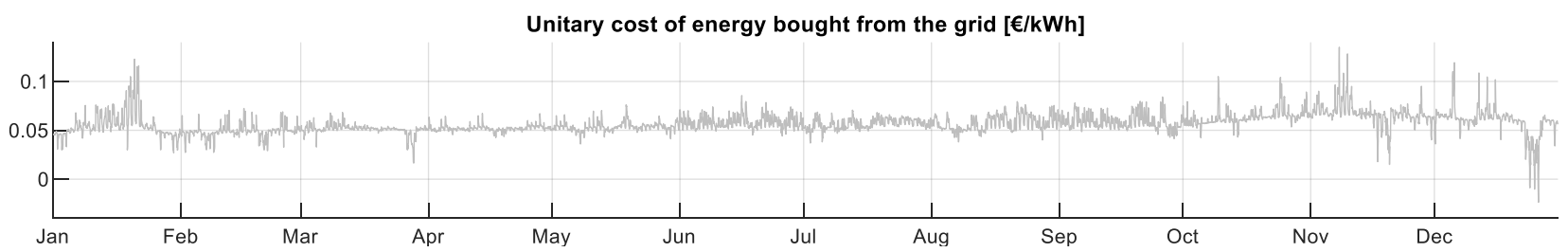

Fig. 6. Profile of unitary buying price.

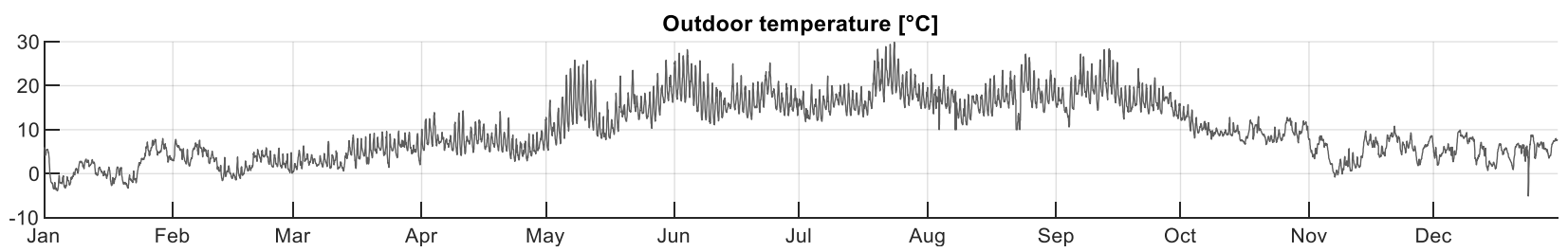

Fig. 7. Profile of outdoor temperature. 
for one hour is estimated at $9 \mathrm{kWh} / \mathrm{h}$. The pre-heating phase is set to 1 hour in case of the naïve energy scheduling.

As for the sauna, it is used four days per week during winter (one 1-hour session in the afternoon) and all the week during summer (one 1-hour session in the early morning and one in the afternoon). The thermal range of use is set to [58-62] ${ }^{\circ} \mathrm{C}$. The settling time of the sauna is estimated to 0.5 hour, whilst the electric consumption of the heater for one hour is estimated at $12 \mathrm{kWh} / \mathrm{h}$.

\subsection{Results Analysis and Discussion}

We consider the energy scheduling of the case study microgrid by applying the above described methods for the five cases of analysis shown in Table 1. The results of the energy scheduling are presented in Figs. 8-10. In Fig. 8, the scheduled aggregated daily energy profiles of CLs (i.e., vector $\boldsymbol{y}$ ) are reported. From Fig. 8 it is apparent that in all the cases the energy consumed by CLs is on average lower during summer since the HVAC system is not used. Figure 9 represents the charging/discharging activities of the BESS (i.e., vector $\boldsymbol{x}^{s+}-\boldsymbol{x}^{s-}$ ). The quantity of energy charged/discharged from/to the BESS is higher in scenario II.a and II.b where the minimization of energy cost is pursued. Finally, Fig. 10 shows the daily energy bought/sold from/to the main grid (i.e., vector $\boldsymbol{x}^{g+}-\boldsymbol{x}^{g-}$ )). From Fig. 10 it is apparent that in all the cases the energy sold to main grid is on average higher in May-June and September-October when the PV production is relatively consistent with respect to the demand.

We now investigate the effects of the proposed method on three indicators: 1) total energy cost, 2) self-supply, and 3) energy-independence. Note that the total energy cost, the self-supply, and the energy-independence are respectively defined as:

$$
\begin{gathered}
E C_{T}=\sum_{t=1}^{T}\left(k^{+}(t) x^{g+}(t)-k^{-}(t) x^{g-}(t)\right) \\
S S_{T}=1-\frac{\sum_{t=1}^{T} x^{g-}(t)}{\sum_{t=1}^{T} r(t)} \\
E I_{T}=1-\frac{\sum_{t=1}^{T} x^{g+}(t)}{\sum_{t=1}^{T} b(t)+y(t)}
\end{gathered}
$$

The first indicator $\left(E C_{T}\right)$ concerns the business economy (cost saving) and has to be minimized. The second and third ones $\left(S S_{T}\right.$ and $\left.E I_{T}\right)$, measured in percentage values, concern the self-reliance of the microgrid and have to maximized. The selfsupply indicates the percentage of the energy totally sold to the main grid to the energy totally produced in the microgrid, whilst the energy-supply indicates the percentage of energy totally bought from the main grid to the energy totally consumed in the microgrid [61].

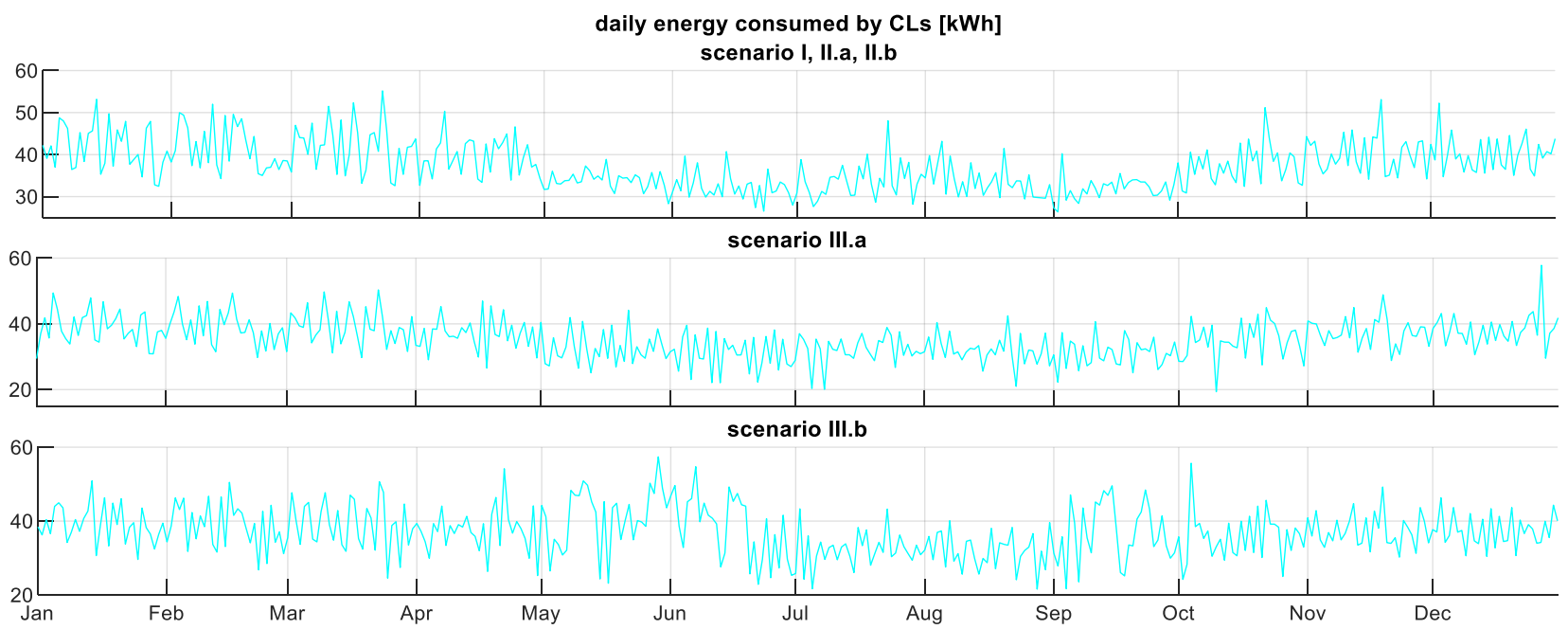

Fig. 8. Daily total and CLs energy consumption profile, for each case of analysis. 

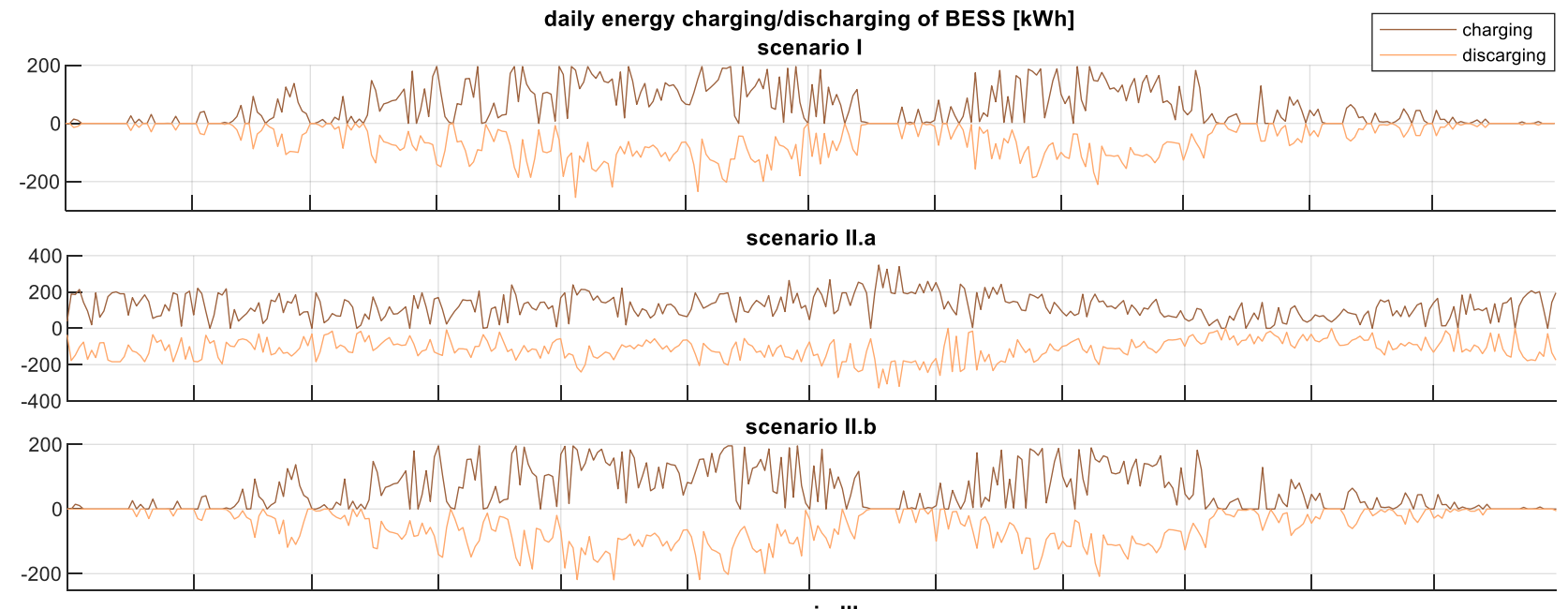

scenario III.a

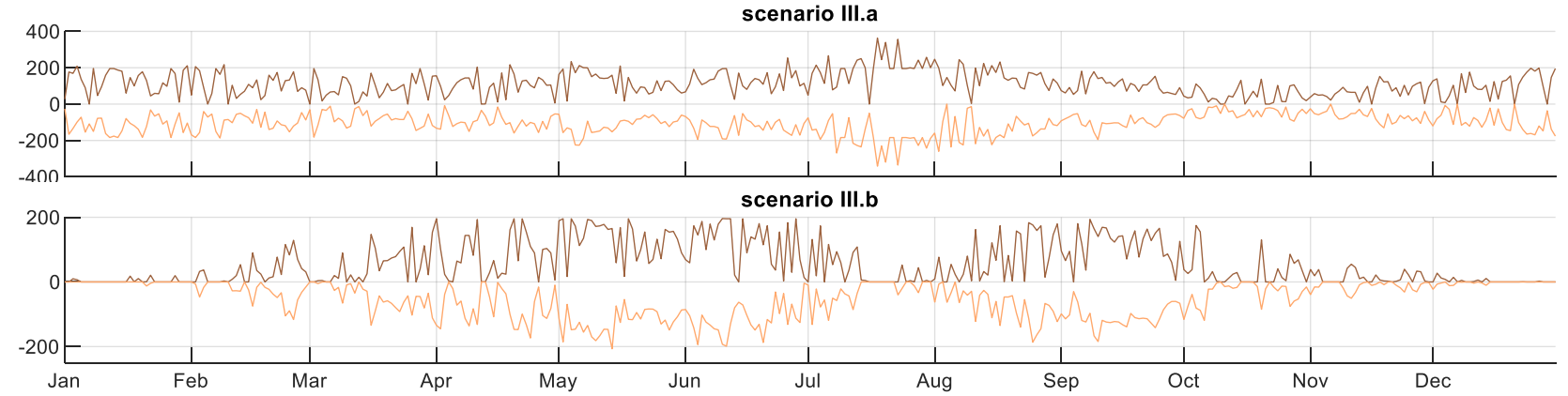

Fig. 9. Daily energy charging/discharging profile of BESS, for each case of analysis.
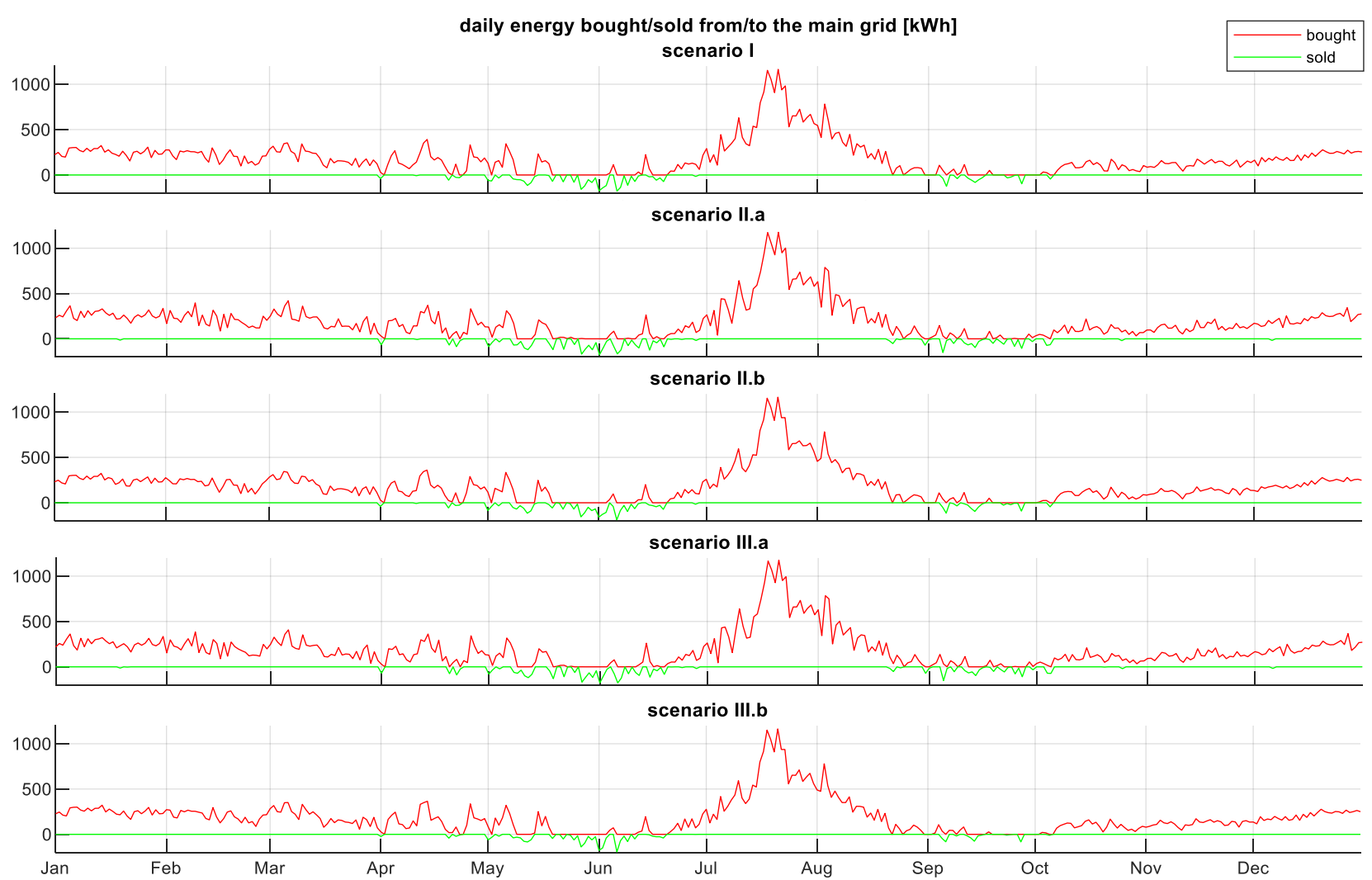

Fig. 10. Daily energy bought/sold from/to the main grid, for each case of analysis. 
Table 2. Comparison of the achieved results.

\begin{tabular}{|c|c|c|c|c|c|c|}
\hline \multirow{2}{*}{ description } & \multirow{2}{*}{ symbol } & \multicolumn{5}{|c|}{ scenario } \\
\hline & & I & II.a & II.b & III.a & III.b \\
\hline $\begin{array}{l}\text { total energy produced by } \\
\text { PV panels [kWh] }\end{array}$ & $\sum_{t=1}^{T} r(t)$ & \multicolumn{5}{|c|}{56,000} \\
\hline $\begin{array}{l}\text { total energy consumed } \\
\text { by NCLs [kWh] }\end{array}$ & $\sum_{t=1}^{T} b(t)$ & \multicolumn{5}{|c|}{104,773} \\
\hline $\begin{array}{l}\text { total energy consumed } \\
\text { by CLs [kWh] }\end{array}$ & $\sum_{t=1}^{T} y(t)$ & 13,656 & 13,656 & 13,656 & 12,923 & 13,585 \\
\hline $\begin{array}{l}\text { total energy bought from } \\
\text { grid [kWh] }\end{array}$ & $\sum_{t=1}^{T} x^{g+}(t)$ & 67,011 & 69,268 & 67,011 & 68,359 & 66,046 \\
\hline $\begin{array}{l}\text { total energy sold to grid } \\
{[\mathrm{kWh}]}\end{array}$ & $\sum_{t=1}^{T} x^{g-}(t)$ & 3,276 & 4,246 & 3,276 & 4,231 & 2,397 \\
\hline total energy cost $[€]$ & $E C_{T}$ & $3,632.10$ & $\begin{array}{l}3,395.20 \\
(-6.5 \%)^{*}\end{array}$ & $3,626.30$ & $\begin{array}{c}\mathbf{3 , 3 3 4 . 8 0} \\
(-8.2 \%)^{*} \\
(-1.8 \%)^{* *}\end{array}$ & $3.608,70$ \\
\hline self-supply & $S S_{T}$ & $94.1 \%$ & $92,4 \%$ & $\begin{array}{l}94,1 \% \\
(+0 \%)^{*}\end{array}$ & $92,4 \%$ & $\begin{array}{c}\mathbf{9 5 , 7 \%} \\
(+1.6 \%)^{*} \\
(+1.6 \%)^{* * *}\end{array}$ \\
\hline energy-independence & $E I_{T}$ & $43.4 \%$ & $41.5 \%$ & $\begin{array}{l}43.4 \% \\
(+0 \%)^{*}\end{array}$ & $41.9 \%$ & $\begin{array}{c}\mathbf{4 4 . 2 \%} \\
(+0,8 \%)^{*} \\
(+0,8 \%)^{* * *}\end{array}$ \\
\hline
\end{tabular}

* with respect to Scenario I, ** with respect to Scenario II.a, *** with respect to Scenario II.b

Table 2 reports the total energy cost incurred by the microgrid in the considered cases of analysis. Moreover, Table 2 shows that in all the cases the PV plant is exploited to around $92-96 \%$ of its annual production. The marina is only $41-44 \%$ energy-independent due to its large consumption compared to the size of the PV production.

The comparison between case I and II.a highlights the economic benefit in using the proposed MPC to optimally control the BESS in the microgrid. In fact, in case of no CLs, the MPC aimed at cost minimization (Algorithm 2a) leads to $6.5 \%$ savings in the total energy cost compared to the naïve approach. Conversely, scenario I and II.b are equivalent from the selfreliance perspective: in other words, an intelligent schedule based on MPC does not improve the result achieved by the naïve approach to the storage charging/discharging strategies. From the self-reliance perspective, the equivalence of Algorithm 1 and Algorithm 2b in scenario I and II.b occurs, since there are only non-controllable loads, PV and storage in the microgrid. The reason is that there is no advantage in further charging storage with energy from grid, if we want to reduce the "dependence" on the main grid (i.e., making the microgrid operate in islanded mode as much as possible), hence:

- selling PV production to the grid -when the battery is not full- is downhearted. Indeed, if the battery charge level is lower than necessary (because it has not been charged from the PV) and there is somehow deficit of production, part of consumption need (that otherwise could be totally supplied by the storage) is mandatorily bought from the grid (this lowers the energy-independence). Thus, selling to the grid -when the battery is full- is privileged.

- charging the battery from the grid -when the battery is not full- is downhearted. Indeed, if the battery charge level is higher than necessary (because it has been charged from the grid) and there is somehow surplus of production, part of this local production (that otherwise could be totally put in the storage) is mandatorily sold to the grid (this lowers the self-supply). Thus, the charge from the PV is privileged.

The comparison between scenarios II.a and II-b and scenarios III.a and III.b highlights the advantages in using the proposed MPC when the microgrid is enhanced with load flexibility. Indeed, the MPC optimal scheduling of CLs generates a performance improvement to the microgrid from both the cost saving and self-reliance perspectives. In the presence of CLs, the MPC aimed at cost minimization (Algorithm 2a) leads to $1.8 \%$ savings in the total energy cost compared to the case of no load flexibility. At the same time, the MPC aimed at self-reliance maximization (Algorithm $2 \mathrm{~b}$ ) leads to $1.6 \%$ and $0.8 \%$ improvement in the self-supply and energy-independence compared to the case of no load flexibility. The reason is that deferring loads leads to smooth out peak consumption, with consequent benefit in terms of costs and self-reliance.

Summing up, it is apparent that the best performance is achieved by the MPC algorithm aimed at controlling the amount of energy to be consumed by each CL, the amount of energy to be charged/discharged into/from the BESS, and the amount 
of bought/sold from/to the grid: the minimum energy cost is achieved by the MPC aimed at cost minimization (Algorithm 2a) saving $8.2 \%$ compared to the naïve approach, whilst the maximum self-supply and energy-independence are achieved by the MPC aimed at self-reliance maximization (Algorithm $2 \mathrm{~b}$ ) improving 1.6\% and $0.8 \%$ compared to the naïve approach, respectively. Hence, on the one hand, we remark that energy cost and self-reliance are competing criteria. Lowering the cost leads to worsing the self-reliance. On the other hand, in scenario III.a - where the minimum energy cost is achieved - the selfsupply and energy-independence are only slightly lower than the optimal values achieved in scenario III.b.

We finally remark that, in order to further maximize renewable energy use and minimize daily cost, further loads could be deferred. For example, the floor heating in the service building can shut off during peak hours, and the peak demand from boats could be smoothed out through tariff incentives.

\section{Conclusions}

Smart energy systems must be developed in close correlation and interplay with advanced control strategies to meet the challenge of integrated fluctuating renewable energy sources (RES) and achieve a balance between generation and consumption. Microgrids with energy storage capacity and load flexibility play a crucial role in this process. Coping with this, we propose a Model Predictive Control (MPC) based energy scheduling for the Demand Side Management (DSM) of a microgrid equipped with non-controllable and controllable electrical appliances, as well as photovoltaic panels, and a battery energy storage system. Then, we assess the attractiveness of the proposed approach through an experimental study using real data related the marina of Ballen, Samsø (Denmark). First, the achieved results demonstrate that MPC implementation for DSM is effective in optimally planning the shared resources (i.e., the storage system charge/discharge and renewable energy usage), controllable loads, and energy exchange with the grid. At the same time, the experimental study showcases the potentials of DSM introduction to the microgrid of the marina.

In general terms, the MPC optimizer without DSM of controllable loads already saves operational costs. Whether the savings outweigh the costs of installing and operating the MPC optimization remains to be calculated, but the optimizer will likely provide $6.5 \%$ savings annually. In addition, DSM of controllable loads improves the economy (8.5\%). The smart energy system may change over time, and staff must be trained to change the algorithmic constraints accordingly. It will also be necessary to build a fail-safe mechanism, which switches to naïve control mode in case of failures. Even the naive mode utilizes the photovoltaic plant well (up to 94\%). The numbers indicate that an MPC optimizer improves the economic viability at the expense of the self-supply with solar energy. The improvement of the economy is larger, in percentages, than the loss of the self-supply. The economy will be the more important of the two. Should it turn out, in the worst case, that an investment in an MPC controller is infeasible, this simulation study has already taught the energy manager of the marina of Ballen some advantageous control strategies, which could be implemented in an inexpensive manner based on a calendar.

Future works will be focused on: enhancing the system model with other components, such as non-interruptible loads, electric vehicles, and distributed generators; assessing how the predictive horizon length affects the performance of the proposed MPC; analysing how increasing the load flexibility could further smooth the demand and improve the scheduling performance. Moreover, we will investigate both the integration of additional terms into the objective function (e.g., a penalty term to capture users' discomfort, operational costs of devices) and trading-off between multiple criteria such as the minimization of microgrid energy cost and maximization of the self-supply with renewable energy sources in a multiobjective optimization. Finally, we shall focus on implementing robust and stochastic variants of MPC to address the uncertainty affecting both measurements and models and thus robustify the resolution of the proposed energy scheduling problem.

\section{Acknowledgement}

This paper presents work that is partially supported by the Horizon 2020 research programme through the project SMILE (Smart Island Energy systems) under grant agreement no. 731249. The article is based on an oral presentation delivered at the 5th conference on Smart Energy Systems (SES) in Copenhagen, Denmark, September 10-11, 2019.

\section{References}

[1] Piacentino, A., Duic, N., Markovska, N., Mathiesen, B. V., Guzović, Z., Eveloy, V., \& Lund, H. (2019). Sustainable and cost-efficient energy supply and utilisation through innovative concepts and technologies at regional, urban and single-user scales, Energy, Volume 182, pp. 254-268.

[2] Ranieri, L., Mossa, G., Pellegrino, R., \& Digiesi, S. (2018). Energy recovery from the organic fraction of municipal solid waste: A real options-based facility assessment. Sustainability, 10(2), 368.

[3] Kılkış, Ş. (2015). Composite index for benchmarking local energy systems of Mediterranean port cities. Energy, 92, 622-638.

[4] X. Fang, S. Misra, G. Xue, and D. Yang. Smart grid - the new and improved power grid: A survey. IEEE Communications Surveys Tutorials, 
14(4):944-980, 2012.

[5] R. Ma, H.-H. Chen, Y.-R. Huang, and W. Meng, "Smart grid communication: Its challenges and opportunities," IEEE Trans. Smart Grid, vol. 4, no. 1, pp. 36-46, Mar. 2013.

[6] Talarico, C., D'Amato, G., Coviello, G., \& Avitabile, G. (2015). A high precision phase control unit for DDS-based PLLs for 2.4-GHz ISM band applications. IEEE 58th International Midwest Symposium on Circuits and Systems (MWSCAS) (pp. 1-4)

[7] G. Casalino, G. Castellano and C. Mencar, (2018), Incremental adaptive semi-supervised fuzzy clustering for data stream classification, IEEE Conference on Evolving and Adaptive Intelligent Systems (EAIS), pp. 1-7.

[8] H. Lund, S. Werner, R. Wiltshire, S. Svendsen, J.E. Thorsen, F. Hvelplund and B.V. Mathiesen. 4th Generation District Heating (4GDH). Integrating smart thermal grids into future sustainable energy systems. Energy, Vol 68, pp. 1-11, April 2014.

[9] You H. Lund, P.A. Østergaard, M. Chang, S. Werner, S. Svendsen, P. Sorknæs, J.E. Thorsen, F. Hvelplund, B. O. Gram Mortensen, B. V. Mathiesen, C. Bojesen, N. Duic, X. Zhang, B. Möller. The status of 4th generation district heating: Research and results. Energy, Vol 164, pp. 147-159, December 2018

[10] H. Lund, P. A. Østergaard, D Connolly, B. V. Mathiesen: Smart energy and smart energy systems. Energy, Vol 137, pp. 556-565, October 2017.

[11] P. Palensky and D. Dietrich, "Demand side management: Demand response, intelligent energy systems, and smart loads," IEEE Transactions on Industrial Informatics, vol. 7, no. 3, pp. 381;388, Jun. 2011.

[12] Guelpa, E., Marincioni, L., Deputato, S., Capone, M., Amelio, S., Pochettino, E., \& Verda, V. (2019). Demand side management in district heating networks: A real application. Energy, 182, 433-442.

[13] Leitner, B., Widl, E., Gawlik, W., \& Hofmann, R. (2019). A method for technical assessment of power-to-heat use cases to couple local district heating and electrical distribution grids. Energy, 182, 729-738.

[14] Gelazanskas, L., \& Gamage, K. A. (2014). Demand side management in smart grid: A review and proposals for future direction. Sustainable Cities and Society, 11, 22-30.

[15] Kakran, S., \& Chanana, S. (2018). Smart operations of smart grids integrated with distributed generation: A review. Renewable and Sustainable Energy Reviews, 81, 524-535.

[16] B.V. Mathiesen, H. Lund, D. Connolly, H. Wenzel, P.A. Østergaard, B. Möller, S. Nielsen, I. Ridjan, P. Karnøe, K. Sperling and F.K. Hvelplund. Smart Energy Systems for coherent 100\% renewable energy and transport solutions. Applied Energy, Vol 145, pp. 139-154, May 2015.

[17] H. Lund, P.A. Østergaard, D. Connolly, I. Ridjan, B.V. Mathiesen, F. Hvelplund, J.Z .Thellufsen, P. Sorknæs: Energy Storage and Smart Energy Systems, International Journal of Sustainable Energy Planning and Management Vol 11, March 2016.

[18] Y. Fujimoto et al., Distributed energy management for comprehensive utilization of residential photovoltaic outputs, IEEE Trans. Smart Grid, vol. 9, no. 2, pp. 1216-1227, Mar. 2018.

[19] Javaid, N., Hafeez, G., Iqbal, S., Alrajeh, N., Alabed, M. S., \& Guizani, M. (2018). Energy efficient integration of renewable energy sources in the smart grid for demand side management. IEEE Access, 6, 77077-77096.

[20] Giordano, A., Mastroianni, C., Menniti, D., Pinnarelli, A., Scarcello, L., \& Sorrentino, N. (2019). A Two-Stage Approach for Efficient Power Sharing Within Energy Districts. IEEE Transactions on Systems, Man, and Cybernetics: Systems.

[21] Digiesi, S., Mossa, G., \& Mummolo, G. (2013). Supply lead time uncertainty in a sustainable order quantity inventory model. Management and Production Engineering Review, 4(4), 15-27.

[22] J. Ma, H. H. Chen, L. Song and Y. Li, "Residential load scheduling in smart grid: a cost efficiency perspective," IEEE Trans. Smart Grid, 7: 771-784, 2016.

[23] Yang, R., \& Wang, L. (2012). Multi-objective optimization for decision-making of energy and comfort management in building automation and control. Sustainable Cities and Society, 2(1), 1-7.

[24] Arun, S. L., \& Selvan, M. P. (2017). Dynamic demand response in smart buildings using an intelligent residential load management system. IET Generation, Transmission \& Distribution, 11(17), 4348-4357.

[25] Lee, S., Lee, J., Jung, H., Cho, J., Hong, J., Lee, S., \& Har, D. (2019). Optimal power management for nanogrids based on technical information of electric appliances. Energy and Buildings, 191, 174-186.

[26] Ye, F., Qian, Y., \& Hu, R. Q. (2015). A real-time information based demand-side management system in smart grid. IEEE Transactions on Parallel and Distributed Systems, 27(2), 329-339.

[27] Liu, D., Xu, Y., Wei, Q., \& Liu, X. (2017). Residential energy scheduling for variable weather solar energy based on adaptive dynamic programming. IEEE/CAA Journal of Automatica Sinica, 5(1), 36-46.

[28] Mahmud, K., Hossain, M. J., \& Town, G. E. (2018). Peak-load reduction by coordinated response of photovoltaics, battery storage, and electric vehicles. IEEE Access, 6, 29353-29365.

[29] Rahimiyan, M., \& Baringo, L. (2015). Strategic bidding for a virtual power plant in the day-ahead and real-time markets: A price-taker robust optimization approach. IEEE Transactions on Power Systems, 31(4), 2676-2687.

[30] Fratean, A., \& Dobra, P. (2018). Control strategies for decreasing energy costs and increasing self-consumption in nearly zero-energy buildings. Sustainable cities and society, 39, 459-475.

[31] Serale, G., Fiorentini, M., Capozzoli, A., Bernardini, D., \& Bemporad, A. (2018). Model predictive control (MPC) for enhancing building and HVAC system energy efficiency: Problem formulation, applications and opportunities. Energies, 11(3), 631.

[32] Yi Zong, Georg Martin Böning, Rui Mirra Santos (2016), "Challenges of Implementing Economic Model Predictive Control Strategy for Buildings Interacting with Smart Energy Systems", Journal of Applied Thermal Engineering, Vol.114, 1476-1486.

[33] Kolokotsa, D., Pouliezos, A., Stavrakakis, G., \& Lazos, C. (2009). Predictive control techniques for energy and indoor environmental quality management in buildings. Building and Environment, 44(9), 1850-1863.

[34] Li, S., Yang, J., Song, W., \& Chen, A. (2018). A Real-Time Electricity Scheduling for Residential Home Energy Management. IEEE Internet of Things Journal, 6(2), 2602-2611.

[35] Hosseini, S. M., Carli, R., \& Dotoli, M. (2018). Model predictive control for real-time residential energy scheduling under uncertainties. IEEE International Conference on Systems, Man, and Cybernetics (SMC) (pp. 1386-1391).

[36] Long, S., Marjanovic, O., \& Parisio, A. (2019). Generalised control-oriented modelling framework for multi-energy systems. Applied Energy, 235, 320-331.

[37] Nguyen, D. B., Scherpen, J. M., \& Bliek, F. (2017). Distributed optimal control of smart electricity grids with congestion management. IEEE Transactions on Automation Science and Engineering, 14(2), 494-504. 
[38] Yang, X., Zhang, Y., He, H., Ren, S., \& Weng, G. (2018). Real-time demand side management for a microgrid considering uncertainties. IEEE Transactions on Smart Grid, 10(3), 3401-3414.

[39] Prodan, I., \& Zio, E. (2014). A model predictive control framework for reliable microgrid energy management. International Journal of Electrical Power \& Energy Systems, 61, 399-409.

[40] Du, Y., Wu, J., Li, S., Long, C., \& Onori, S. (2019). Coordinated Energy Dispatch of Autonomous Microgrids with Distributed MPC Optimization. IEEE Transactions on Industrial Informatics.

[41] A. La Bella, S. Raimondi Cominesi, C. Sandroni, and R. Scattolini. Hierarchical predictive control of microgrids in islanded operation. IEEE Transactions on Automation Science and Engineering, 14(2):536-546, 2017.

[42] Oh, S., Chae, S., Neely, J., Baek, J., \& Cook, M. (2017). Efficient model predictive control strategies for resource management in an islanded Microgrid. Energies, 10(7), 1008.

[43] Pippia, T., Sijs, J., \& De Schutter, B. 2018. A Parametrized Model Predictive Control Approach for Microgrids. 2018 IEEE Conference on Decision and Control (CDC) pp. 3171-3176.

[44] Zhang Q, Grossmann IE. Enterprise-wide optimization for industrial demand side management: Fundamentals, advances, and perspectives. Chemical Engineering Research and Design 2016, 116:114-131.

[45] Matthews, B., \& Craig, I. K. (2013). Demand side management of a run-of-mine ore milling circuit. Control Engineering Practice, 21(6), $759-768$.

[46] Van Staden, A. J., Zhang, J., \& Xia, X. (2011). A model predictive control strategy for load shifting in a water pumping scheme with maximum demand charges. Applied Energy, 88(12), 4785-4794.

[47] Jin, H., Li, Z., Sun, H., Guo, Q., \& Wang, B. (2017). Coordination on Industrial Load Control and Climate Control in Manufacturing Industry Under TOU Prices. IEEE Transactions on Smart Grid, 10(1), 139-152.

[48] Garcia, C. E., Prett, D. M., \& Morari, M. (1989). Model predictive control: theory and practice—a survey. Automatica, 25(3), 335-348.

[49] Esther, B. P., \& Kumar, K. S. (2016). A survey on residential demand side management architecture, approaches, optimization models and methods. Renewable and Sustainable Energy Reviews, 59, 342-351.

[50] Ramanathan, B., \& Vittal, V. (2008). A framework for evaluation of advanced direct load control with minimum disruption. IEEE Transactions on Power Systems, 23(4), 1681-1688.

[51] A. Parisio, E. Rikos, and L. Glielmo, "A model predictive control approach to microgrid operation optimization," IEEE Trans. Control Syst. Technol., vol. 22, no. 5, pp.1813-1827, 2014.

[52] R. Carli and M. Dotoli, "Decentralized control for residential energy management of a smart users' microgrid with renewable energy exchange," IEEE/CAA J. Autom. Sin., vol. 6, no. 3, pp. 641-656, May 2019.

[53] S. Paul and N. P. Padhy, "Resilient scheduling portfolio of residential devices and plug-in electric vehicle by minimizing conditional value at risk," IEEE Trans. Industr. Inform., vol. 15, no. 3, pp. 1566-1578, Mar. 2019.

[54] Jantzen J. Requirements Specification: Deliverable D3.4 [Internet]. SMILE; 2019. Available from: https://www.h2020smile.eu (Accessed on: 2019, August).

[55] IBM, IBM ILOG CPLEX Optimization Studio Getting Started with CPLEX for MATLAB, https://www.ibm.com/support/knowledgecenter /en/SSSA5P_12.6.2/ilog.odms.cplex.help/CPLEX/MATLAB/topics/gs .html. (Accessed on: 2019, August).

[56] Østergaard, P. A., Jantzen, J., Marczinkowski, H. M., \& Kristensen, M. (2019). Business and socioeconomic assessment of introducing heat pumps with heat storage in small-scale district heating systems. Renewable energy, 139, 904-914.

[57] J. Jantzen, M. Kristensen, T.H. Christensen, Sociotechnical transition to smart energy: the case of Samso 1997-2030, Energy, 162 (2018) $20-34$.

[58] Marczinkowski, H. M., \& Østergaard, P. A. (2019). Evaluation of electricity storage versus thermal storage as part of two different energy planning approaches for the islands Samsø and Orkney. Energy, 175, 505-514.

[59] http://arkiv.energiinstituttet.dk/643/ (Accessed on: 2019, August).

[60] https://www.nordpoolgroup.com/Market-data1/Dayahead/Area-Prices/ALL1/Hourly/?view=table (Accessed on: 2019, August).

[61] Kim, M., Parkt, S., Choi, J. K., \& Lee, J. (2017). Energy independence of energy trading system in microgrid. IEEE Innovative Smart Grid Technologies-Asia (ISGT-Asia) (pp. 1-4). 